\title{
Effects of fuzzy data on decision making in a competitive supply chain
}

\author{
Shih-Pin Chen ${ }^{1 *}$ \\ ${ }^{1}$ Department of Business Administration, National Chung Cheng University, 168, University Road, Ming-Hsiung, \\ Chia-Yi 621, Taiwan
}

The essence of data plays a critical role in decision making in supply chain management (SCM). When data embedded in supply chains (SCs) are fuzzy, the associated equilibrium and performance measures also become fuzzy. This paper investigates the effects of fuzzy data on decision making in a two-echelon SC with a supplier and duopolistic retailers playing a Stackelberg strategic game in both intra- and inter-echelons. In contrast to existing approaches, this paper devises an analysis method to provide a likely interval of the fuzzy maximal profit with a known possibility level (degree of certainty) rather than a singleton (crisp value). The idea is based on the extension principle to reformulate the two-level optimization problem as a pair of parametric quadratic programs in order to calculate the lower and upper bounds of the leader's fuzzy maximal profit at each possibility level of the obtained information. The analytic results indicate that the higher the degree of uncertainty, the smaller (larger) the lower (upper) bound of the maximum profit of each SC member. Moreover, the main results obtained from eight scenarios show that when the degree of demand diversity between the two retailers is significantly high, the Stackelberg leader is most likely to obtain lower profit and the marginal contribution of the primary demand to the total profit of the duopolistic retailers will exceed that of the powerful supplier's maximum profit. Journal of the Operational Research Society (2017) 68(10), 1146-1160. doi:10.1057/s41274-016-0138-7; published online 14 December 2016

Keywords: game theory; imprecise data; pricing; supply chain management

\section{Introduction}

Supply chain management (SCM), one of the most attractive research areas in applied operational research (OR), has become increasingly important in all types of organizations given the current highly competitive and globalized business environment. This subject involves directing and organizing activities throughout the entire supply chain (SC) to maximize customer value and achieve a sustainable competitive advantage (SimchiLevi et al, 2004, 2007). Classical research on this topic includes works by Lee and Billington (1992), Lee et al (1997), Chen (1999), Chen et al (2000), Graves and Willems (2005), Miles and Snow (2007), Chick et al (2008), Gunasekaran et al (2008), and Iida and Zipkin (2010). See Kouvelis et al (2006), Iida and Zipkin (2010), and Farahani et al (2014) for comprehensive reviews.

Considerable research has been conducted on the competitiveness of SCs with different power structures to characterize the competitive behaviors among the SC members existing in real-world SCs. Such studies have focused on several games such as Nash, Cournot, Collusion and Stackelberg games (e.g.,

*Correspondence: Shih-Pin Chen, Department of Business Administration, National Chung Cheng University, 168, University Road, Ming-Hsiung, Chia-Yi 621, Taiwan.

E-mail: chensp@ccu.edu.tw
Choi, 1996; Yang and Zhou, 2006; Xia, 2011; Wu et al, 2012; Zhao et al, 2014; Modak et al, 2016). For example, Choi (1991) developed manufacturer-Stackelberg, retailer-Stackelberg, and vertical Nash pricing models to investigate optimal pricing decisions in a two-echelon SC with two competitive manufactures selling partially substitutable products through a common retailer. Choi (1996) studied a SC with two competing manufacturers and two common retailers that selling competing brands. Xia (2011) investigated the competitive strategies between two sellers providing substitutable goods in a multi-buyer marketplace. Yang and Zhou (2006) studied the pricing and quantity decisions of a twoechelon SC with one manufacturer and two retailers, where the manufacturer is a Stackelberg leader and the competition between retailers includes Cournot, Stackelberg and collusion games. Wu et al (2012) investigated the equilibrium decisions in a SC with one common supplier and two retailers and considered six power structures of vertical and horizontal competition. Zhao et al (2014) developed one centralized pricing model and seven decentralized pricing models to analyze the pricing decisions for substitutable products in a two-echelon SC consisting of one common retailer and two competitive manufacturers.

Note that among the different strategic games for describing various power structures among members in real-world SCs, several studies have focused on the Stackelberg game 
(recently, e.g., Xiao et al, 2014; Yang et al, 2015; Wang et al, 2016). This paper focuses on the case of SC members playing a Stackelberg game in both intra- and inter-echelons because such a power structure may appear in real-world situations. Regarding vertical competition, as a real-world SC example, Microsoft plays a more dominant role than downstream members (Ertek and Griffin, 2002). With regard to horizontal competition between two retailers, a practical example is that the UK grocery retailer Tesco followed Walmart in entering the India market (Domain-b.com, 2008; Ryan, 2008). Another practical example is the competition in Taiwan's fixed network market. After the opening of this license in 2000, three private companies [that is, Taiwan Fixed Network (TFN), New Century InfoComm (NCIC), and Eastern Broadband Telecom (EBT)] followed the dominant leader Chunghwa Telecom (the largest telecommunications company in Taiwan) in entering the fixed network market in Taiwan. Prior studies have also discussed the topic of two competitive retailers playing games such as the Stackelberg game; for example, Modak et al (2016) recently noted that "the duopolistic retailers may compete with each other following Stackelberg" and investigated the pricing decisions in a threeechelon SC with one manufacturer and two retailers playing Cournot, Stackelberg, and Collusion games.

Many sources of uncertainties exist in a SC, such as market demand and lead times (Petrovic et al, 1998; Petrovic, 2001). One of the pitfalls of SCM presented by Lee and Billington (1992) is "ignoring the impact of uncertainties." They noted that "to reduce the impact of these uncertainties, supply chain managers must first understand their sources and the magnitude of their impact." In fact, many previous models have dealt with uncertainties of SCM by assuming that these uncertainties are stochastic (e.g., Lariviere, 1999; Kraiselburd et al, 2004). However, because of the market turbulence characterized by increasingly short product life cycles (PLCs) (Krajewski et al, 2009), data on SCs are often either unreliable or unavailable (e.g., a lack of historical data for the introduction of a new product). Specifically, it is difficult to precisely estimate market demand over a short time period. Imprecise input data of this type will clearly undermine the quality of decisions that are made using conventional stochastic models. That is, SCs in the real world are highly likely to be burdened by uncertainties in the nonstochastic sense (Zimmermann, 2001; Wong and Lai, 2011; Giannoccaro et al, 2003). Therefore, the effect of imprecise data on making an effective SC pricing or quantity decisions must be carefully investigated (Lee and Billington, 1992).

In practice, the forecast market demands are more appropriately described by linguistic terms, such as being approximately equal to certain amounts that are subjectively estimated based on the judgment and intuitions of decision makers. Fuzzy set theory (Zadeh, 1965, 1978; Bellman and Zadeh, 1970) provides an alternative approach to manage SC nonstochastic uncertainties (Petrovic et al, 1999; Giannoccaro et al, 2003;
Peidro et al, 2009, 2010; Wang and Shu, 2005, 2007; Xie et al, 2006). In fact, fuzzy set theory has been successfully applied to SCM problems, and several articles have demonstrated that fuzzy SCM modeling is more suitable in practice than crisp modeling (for example, Peidro et al, 2009). Peidro et al (2009) and Wong and Lai (2011) provided comprehensive reviews of the research related to this topic.

Relatively few studies have investigated the competitive SC problem in fuzzy environments. For example, Zhou et al (2008) discussed the pricing decisions for a single product in a two-echelon SC with fuzzy demands and playing games. Zhao et al (2012a) studied the pricing decisions for substitutable products in a SC with one manufacturer and two competitive retailers in fuzzy environments, and Zhao et al (2012b) discussed the similar problem for a SC with two competitive manufacturers and one common retailer. Moreover, fewer studies have addressed the SCM problem with both horizontal and vertical competition in fuzzy environments. For example, Wei and Zhao (2016) discussed the pricing problem of this type in a SC with two suppliers and one common retailer. However, the decisions obtained from existing models are typically crisp (single-valued numeric), which could result in a loss of important information because the performance measures or equilibrium of the SC could be over- or underestimated. This is similar to the advantage of using interval estimation over point estimation for stochastic data analysis in practice. Therefore, the possible intervals (effective lower and upper bounds) of equilibrium and performance measures with degrees of uncertainty will clearly provide more information and thus they deserve further investigation. Furthermore, few studies have addressed the effect of imprecise data on decision making in SCs.

This paper investigates the effect of imprecise data on the pricing strategy in two-echelon SCs with price-sensitive demand and Stackelberg strategic games played in vertical and horizontal competitions. The analysis method is based on fuzzy set theory and optimization theory. Specially, it follows Zadeh's extension principle, which is one of the most important concepts in fuzzy set theory (Zadeh, 1978; Yager, 1986).

This paper is organized as follows. In Section 2, the mathematical modeling of the two-echelon SC with both horizontal and vertical competition playing Stackelberg games in fuzzy environments is introduced. Next, a membership function approach based on Zadeh's extension principle is adopted to derive the membership functions of SC performance measures. In this approach, a pair of two-level mathematical programs is initially developed and subsequently transformed into a pair of quadratic programs in order to calculate the $\alpha$-cuts of the Stackelberg-leader's fuzzy maximum profit. By enumerating different values of $\alpha$, the membership function of the fuzzy maximum profit is constructed, and the corresponding optimal pricing and quantity decisions are derived. Section 4 presents the solutions to eight scenarios within an example application inspired by 
previous studies. Most important, the managerial implications are discussed in Section 5. Finally, Section 6 concludes this paper.

\section{Fuzzy Competitive SCs}

Consider a two-echelon SC with a monopolistic supplier (manufacturer/seller) and two duopolistic retailers (buyers) facing both vertical and horizontal competitions. The vertical competition structure between two echelons is supplier-Stackelberg (von Stackelberg, 1952); the supplier acts as a leader and determines a unit wholesale price $w$ for the two retailers, and these two retailers (acting as followers) then independently determine the unit sale prices, $p_{i}, i=1,2$, charged to customers. Normally, the unit wholesale price is smaller than the unit sale prices, i.e., $w<p_{i}, i=1,2$. In addition, the horizontal competition structure between these two retailers, which represents the retailers' competitive behavior, is also Stackelberg. Most important, forecast market demands faced by SC members are described by linguistic terms, which are subjectively estimated based on the judgment and intuitions of decision makers. The problem is to determine an optimal price that maximizes the profit for each SC member.

The proposed model is constructed under the following key assumptions, which are similar to those made by Ingene and Parry (1995):

1. Each decision maker pursues profit maximization.

2. No resale of products between retailers is allowed.

3. No backorders are allowed.

4. The demand functions encountered by the two retailers are price sensitive with the following downward sloping forms (McGuire and Staelin, 1983; Ingene and Parry, 1995):

$$
Q_{i}\left(p_{i}, p_{j}\right)=\tilde{D}_{i}-a_{i} p_{i}+\theta p_{j}, \quad i=1,2 ; \quad j=3-i,
$$

where $\tilde{D}_{i}>0,0 \leq \theta<a_{i}, i=1,2$. The intercept term $\tilde{D}_{i}$ is the fuzzy market base (also called the primary demand), denoting a measure of the demand confronting the $i$ th retailer if prices are zero. The price parameter $a_{i}$ is a measure of the sensitivity of the $i$ th retailer's sales to changes in its price, and the cross-price parameter $\theta$ is a measure of the sensitivity of the $i$ th retailer's sales to changes in the $j$ th retailer's price. The ratio $\theta / a_{i}$ is the degree of substitutability between the retailers. The condition of $\theta / a_{i}<1$, or $0 \leq \theta<a_{i}$, indicating that changes in $p_{i}$ affect the $i$ th retailer's own demand more than changes in its rival's price $p_{j}$, is typically required to ensure the proper behavior of the demand function. In practice, the demand function is usually estimated using consumer surveys (interviews, questionnaires, or focus groups), market experiments, or econometric techniques, such as regression analysis, which may be the most frequently used technique (Berndt, 1991; Dean, 1980; Thomas and Maurice, 2007).
First, consider the horizontal competition structure in the downstream market. One of the two duopolistic retailers acts as a Stackelberg leader, and the other acts as a Stackelberg follower. Without a loss of generality, assume that the first retailer is the leader in the horizontal competition. Because the leader knows the follower's pricing decision and sets the unit sale price $p_{1}$ to maximize his profit, retailer 1 knows retailer 2's optimal reaction function, which can be derived by maximizing retailer 2's profit. For a pre-specified market base $d_{2}$, as well as a unit wholesale price $w$ and a unit sale price $p_{1}$, as announced by the supplier and retailer 1 , respectively, the profit function of retailer 2 , which equals the total revenue less the total purchasing cost, is as follows:

$$
\Pi_{r 2}\left(p_{2} \mid w, p_{1}\right)=\left(p_{2}-w\right) Q_{2}=\left(p_{2}-w\right)\left(d_{2}-a_{2} p_{2}+\theta p_{1}\right) .
$$

Under the constraints of $p_{2}>w$ and $Q_{2}\left(p_{1}, p_{2}\right)=$ $d_{2}-a_{2} p_{2}+\theta p_{1} \geq 0$, maximizing (2) can derive retailer 2's optimal reaction function. Because it is clear that $\Pi_{r 2}\left(p_{2} \mid w, p_{1}\right)$ is concave with respect to $p_{2}$, its global maximum can be derived by taking the first-order partial derivative of $\Pi_{r 2}\left(p_{2} \mid w, p_{1}\right)$ with respect to $p_{2}$ and setting it to zero while treating $w$ and $p_{1}$ as parameters, which yields the following optimal reaction function for retailer 2 :

$$
p_{2}^{*}=\frac{d_{2}+a_{2} w+\theta p_{1}}{2 a_{2}} .
$$

Substituting this function into retailer 1's profit function, under the conditions of $p_{1}-w>0$ and $Q_{1}\left(p_{1}, p_{2}\right)=d_{1}-a_{1} p_{1}+$ $\theta p_{2} \geq 0$ given a pre-specified market base $d_{1}$, for a prespecified unit wholesale price $w$ announced by the supplier, yields the following:

$$
\begin{aligned}
& \Pi_{r 1}\left(p_{1} \mid w\right)=\left(p_{1}-w\right) Q_{1}=\left(p_{1}-w\right)\left(d_{1}-a_{1} p_{1}+\theta p_{2}\right) \\
& =\left(p_{1}-w\right)\left(2 a_{2} d_{1}-2 a_{1} a_{2} p_{1}+\theta d_{2}+\theta^{2} p_{1}+a_{2} \theta w\right) / 2 a_{2} .
\end{aligned}
$$

Because $\theta<a_{i}, i=1,2$, it is clear that the profit function (4) is concave with respect to $p_{1}$. Similarly, taking the first-order partial derivative of $\Pi_{r 1}\left(p_{1} \mid w\right)$ with respect to $p_{1}$ and setting to zero yield the following:

$$
p_{1}^{*}=\frac{2 a_{2} d_{1}+\theta d_{2}+\left(2 a_{1} a_{2}+a_{2} \theta-\theta^{2}\right) w}{2\left(2 a_{2} a_{1}-\theta^{2}\right)} .
$$

Note that Eq. (5) is parameterized by $w$. Because $Q_{1}=$ $\left(2 a_{2} d_{1}-2 a_{1} a_{2} p_{1}+\theta d_{2}+\theta^{2} p_{1}+a_{2} \theta w\right) / 2 a_{2} \geq 0$ is required for Eq. (4) to be meaningful, we have $2 a_{2} d_{1}+\theta d_{2}+a_{2} \theta w>2 a_{1} a_{2} p_{1}-\theta^{2} p_{1}$. Thus, we have

$$
p_{1}^{*}-w=\frac{2 a_{2} d_{1}+\theta d_{2}+\left[\theta\left(a_{2}+\theta\right)-2 a_{1} a_{2}\right] w}{2\left(2 a_{2} a_{1}-\theta^{2}\right)}>0 .
$$


Therefore, if $Q_{1}\left(p_{1}, p_{2}\right)=d_{1}-a_{1} p_{1}^{*}+\theta p_{2}^{*} \geq 0$, then $p_{1}^{*}$ is the global maximum solution to Eq. (5), which is indeed retailer 1 's optimal reaction function.

In the vertical competition structure, the supplier is a Stackelberg leader; therefore, it knows retailers' optimal reaction functions (3) and (5) and thus their pricing decisions $p_{1}^{*}$ and $p_{2}^{*}$. Therefore, the supplier's profit function can be stated as follows:

$$
\Pi_{S}(w)=(w-c)\left(Q_{1}^{*}+Q_{2}^{*}\right),
$$

where $c$ is the unit manufacturing cost and $Q_{i}^{*}=d_{i}-a_{i} p_{i}^{*}+$ $\theta p_{j}^{*}, i, j=1,2 ; i \neq j$, as shown in (1), $p_{1}^{*}$ is listed in (5), and $p_{2}^{*}$ is listed in Eq. (3). Substituting $p_{1}^{*}$ into Eq. (3) yields the following:

$$
\begin{aligned}
p_{2}^{*} & =\frac{d_{2}+a_{2} w+\theta p_{1}^{*}}{2 a_{2}} \\
& =\frac{2 a_{2} \theta d_{1}+4 a_{1} a_{2} d_{2}-\theta^{2} d_{2}+\left(4 a_{1} a_{2}^{2}+2 a_{1} a_{2} \theta-a_{2} \theta^{2}-\theta^{3}\right) w}{4 a_{2}\left(2 a_{1} a_{2}-\theta^{2}\right)}
\end{aligned}
$$

Specifically,

$$
Q_{1}^{*}=\frac{2 a_{2} d_{1}+\theta d_{2}+\left(\theta^{2}+a_{2} \theta-2 a_{1} a_{2}\right) w}{4 a_{2}},
$$

and

$Q_{2}^{*}=\frac{2 a_{2} \theta d_{1}+4 a_{1} a_{2} d_{2}-\theta^{2} d_{2}+\left(-4 a_{1} a_{2}^{2}+2 a_{1} a_{2} \theta+3 a_{2} \theta^{2}-\theta^{3}\right) w}{4\left(2 a_{1} a_{2}-\theta^{2}\right)}$.

Consequently, the supplier's optimal unit wholesale price $w^{*}$ can be determined by solving the following mathematical program:

$$
\begin{aligned}
Z_{S}=\max & \Pi_{S}(w)=(w-c)\left(Q_{1}^{*}+Q_{2}^{*}\right) \\
\text { s.t. } & w-c \geq \varepsilon>0, \\
& Q_{1}^{*}, Q_{2}^{*} \geq 0,
\end{aligned}
$$

where $\varepsilon$ is a small non-Archimedean quantity.

Because $\Pi_{S}(w)$ is a concave function with respect to $w$, given that $w>c$ and $Q_{i}^{*} \geq 0, i=1,2$, the maximum solution can be derived by setting its first-order derivative $d \Pi_{S}(w) / d w$ to zero, which yields the following:

$$
\begin{aligned}
w^{*} & =\frac{c}{2} \\
& +\frac{4 a_{1} a_{2}^{2}\left(d_{1}+d_{2}\right)+2 a_{2}\left(a_{2} d_{1}+a_{1} d_{2}\right) \theta-a_{2}\left(2 d_{1}+d_{2}\right) \theta^{2}-d_{2} \theta^{3}}{2\left[4 a_{1} a_{2}^{2}\left(a_{1}+a_{2}\right)-4 a_{1} a_{2}^{2} \theta-a_{2}\left(4 a_{1}+3 a_{2}\right) \theta^{2}+2 a_{2} \theta^{3}+\theta^{4}\right]} .
\end{aligned}
$$

In sum, the optimal pricing process in the two-echelon SC with an oligopolistic supplier and duopolistic retailers playing a Stackelberg game is as follows: first, the supplier determines the optimal wholesale price $w^{*}$ according to Model (9); then, the Stackelberg-leader retailer, based on the information from $w^{*}$, determines his optimal sale price according to (5); finally, the Stackelberg-follower retailer decides the optimal sale price according to (3).

Note that the corresponding maximum profit will also be a fuzzy set when some of the uncertainties in the SC are nonstochastic and are appropriately modeled using fuzzy sets. In brief, a fuzzy set is a generalization of the classical (or crisp) set. Mathematically, a fuzzy set $\tilde{B}$ can be described by $\tilde{B}=\left\{\left(x, \mu_{\tilde{B}}(x)\right) \mid x \in X\right\}$, where $\mu_{\tilde{B}}(x)$ is the membership function describing the membership grades of the elements in this set, $x$ is a member or element of the set, and $X$ denotes the universe of discourse (or the universal set) (Zimmermann, 2001).

Without a loss of generality, suppose that the market bases of the retailers are approximately known and can be represented by fuzzy numbers. Note that a fuzzy number $\tilde{F}$ in its universal set $Y$ is a convex and normal fuzzy set, that is, $\mu_{\tilde{F}}\left(\beta y_{1}+(1-\beta) y_{2}\right) \geq \min \left\{\mu_{\tilde{F}}\left(y_{1}\right), \mu_{\tilde{F}}\left(y_{2}\right)\right\}, \quad y_{1}, y_{2} \in Y$, $\beta \in[0,1]$, and its largest membership grade is 1 (Zimmermann, 2001). Because historical data are unavailable or unreliable owing to market turbulence, the market base of retailer $i$ is subjectively described as a fuzzy number $\tilde{D}_{i}=$ $\left\{\left(d_{i}, \mu_{\tilde{D}_{i}}\left(d_{i}\right) \mid d_{i} \in S\left(\tilde{D}_{i}\right)\right\}\right.$ described by a general membership function $\mu_{\tilde{D}_{i}}$ :

$$
\mu_{\tilde{D}_{i}}\left(d_{i}\right)= \begin{cases}L_{i}\left(d_{i}\right), & l_{i} \leq d_{i} \leq m_{i} \\ 1, & m_{i} \leq d_{i} \leq n_{i} \\ R_{i}\left(d_{i}\right), & n_{i} \leq d_{i} \leq u_{i}\end{cases}
$$

where $S\left(\tilde{D}_{i}\right)$ is the support of the fuzzy number $\tilde{D}_{i}$, which denotes the crisp set of all $d_{i}$ such that $\mu_{\tilde{D}_{i}}\left(d_{i}\right)>0, l_{i}>0$, and $L_{i}\left(d_{i}\right)$ and $R_{i}\left(d_{i}\right)$ are the left- and right-shape functions, respectively, of the fuzzy number $\tilde{D}_{i}$. Note that $L_{i}\left(d_{i}\right)$ and $R_{i}\left(d_{i}\right)$ are determined according to the decision maker's subjective judgement, intuitions and experience (Zimmermann, 2001). In fact, the topic of determining the left- and right-shape functions is critical and has been investigated in other studies (for example, Bilgiç and Türkşen, 2000; Türkşen, 1991).

Each different $d_{i}$ in Eq. (11) has a different membership grade described by the membership function $\mu_{\tilde{D}_{i}}$. Based on Zadeh's extension principle, if any of the parameters in Model (9) are fuzzy, then the objective value of this model also becomes fuzzy. Thus, the conventional optimization model for finding the optimal wholesale price $w^{*}$ becomes the following:

$$
\begin{array}{cl}
\tilde{Z}_{S}=\max & (w-c)\left(\tilde{Q}_{1}^{*}+\tilde{Q}_{2}^{*}\right) \\
\text { s.t. } & w \geq c+\varepsilon \\
& \tilde{Q}_{1}^{*}, \tilde{Q}_{2}^{*} \geq 0
\end{array}
$$

where

$$
\tilde{Q}_{1}^{*}=\frac{2 a_{2} \tilde{D}_{1}+\theta \tilde{D}_{2}+\left(\theta^{2}+a_{2} \theta-2 a_{1} a_{2}\right) w}{4 a_{2}},
$$




$$
\begin{aligned}
& \tilde{Q}_{2}^{*} \\
& =\frac{2 a_{2} \theta \tilde{D}_{1}+4 a_{1} a_{2} \tilde{D}_{2}-\theta^{2} \tilde{D}_{2}+\left(-4 a_{1} a_{2}^{2}+2 a_{1} a_{2} \theta+3 a_{2} \theta^{2}-\theta^{3}\right) w}{4\left(2 a_{1} a_{2}-\theta^{2}\right)} .
\end{aligned}
$$

Model (12) is essentially a parametric quadratic program with fuzzy parameters in the objective and a bounded variable. Note that the maximal objective value $\tilde{Z}_{S}$ in Model (12) is fuzzy rather than crisp because different values of $\tilde{D}_{1}$ and $\tilde{D}_{2}$ produce different maximum profits. To precisely measure the impact of vague information on the decision in SC, the fuzziness of input data and output information should be carefully conserved. Specifically, the membership function of $\tilde{Z}_{S}$, denoted by $\mu_{\tilde{Z_{S}}}$, should be derived.

\section{Reformulation Based on the Extension Principle}

The approach adopted here is based on a combination of the $\alpha$ cut concept, Zadeh's extension principle, two-level mathematical programming, and parametric programming. The results derived using this approach conserve the fuzziness of the pricing decision problem in the SC with one supplier and duopolistic retailers playing a Stackelberg game.

On the basis of Zadeh's extension principle, $\tilde{Z}_{S}$ is also a fuzzy number. According to the nested structure property of the membership function of a fuzzy number, the membership function $\mu_{\tilde{Z}_{S}}$ can be constructed by deriving its $\alpha$-cuts (Zimmermann, 2001). Using $\alpha$-cuts, $\tilde{D}_{i}$ can be represented by different levels of confidence intervals. The $\alpha$-cut of $\tilde{D}_{i}$ is a crisp interval that can be expressed in another form as follows:

$$
\begin{aligned}
\left(D_{i}\right)_{\alpha} & =\left[\inf _{d_{i} \in S\left(\tilde{D}_{i}\right)}\left\{d_{i} \mid \mu_{\tilde{D}_{i}}\left(d_{i}\right) \geq \alpha\right\}, \sup _{d_{i} \in S\left(\tilde{D}_{i}\right)}\left\{d_{i} \mid \mu_{\tilde{D}_{i}}\left(d_{i}\right) \geq \alpha\right\}\right] \\
& =\left[\left(D_{i}\right)_{\alpha}^{\mathrm{L}},\left(D_{i}\right)_{\alpha}^{\mathrm{U}}\right] .
\end{aligned}
$$

This interval indicates where the values of $d_{i}$ lie for a given possibility level $\alpha$.

By Zadeh's extension principle (e.g., Zadeh, 1978; Zimmermann, 2001), the membership function $\mu_{\tilde{Z}_{s}}$ is defined as follows:

$$
\mu_{\tilde{Z}_{S}}(z)=\sup _{d_{1}, d_{2} \in R^{+}} \min \left\{\mu_{\tilde{D}_{1}}\left(d_{1}\right), \mu_{\tilde{D}_{2}}\left(d_{2}\right) \mid z=Z_{S}\left(d_{1}, d_{2}\right)\right\},
$$

where $Z_{S}\left(d_{1}, d_{2}\right)$ is defined in Model (9) with parameters $d_{1}$ and $d_{2}$. It is clear that the membership function $\mu_{\tilde{Z}_{S}}$ defined in (15) is parameterized by $\alpha$. According to (14), the $\alpha$-cut of $\tilde{Z}_{S}$ can be expressed as an interval indicating where the values for the supplier's maximum profit lie for a given possibility level $\alpha$. Thus, we can use the $\alpha$-cuts of $\tilde{Z}_{S}$ to construct its membership function. In (19), $\mu_{\tilde{Z}_{S}}$ is the minimum of two other membership functions $\mu_{\tilde{D}_{1}}\left(d_{1}\right)$ and $\mu_{\tilde{D}_{2}}\left(d_{2}\right)$, which complicates the situation. To satisfy $\mu_{\tilde{Z}_{S}}(z)=\alpha$ requires $\mu_{\tilde{D}_{1}}\left(d_{1}\right)=\alpha \quad$ and $\quad \mu_{\tilde{D}_{2}}\left(d_{2}\right) \geq \alpha, \quad$ or $\quad \mu_{\tilde{D}_{1}}\left(d_{1}\right) \geq \alpha \quad$ and $\mu_{\tilde{D}_{2}}\left(d_{2}\right)=\alpha$, such that $z=Z_{S}\left(d_{1}, d_{2}\right)$. The basic idea of this paper is that the membership function $\mu_{\tilde{Z}_{S}}$ can be defined by determining the left-shape function and the right-shape function of $\mu_{\tilde{Z}_{S}}$, which is equivalent to finding the lower bound $\left(Z_{S}\right)_{\alpha}^{\mathrm{L}}$ and the upper bound $\left(Z_{S}\right)_{\alpha}^{\mathrm{U}}$ of the $\alpha$-cut of $\tilde{Z}_{S}$ :

$$
\left(Z_{S}\right)_{\alpha}^{\mathrm{L}}=\min \left\{Z\left(d_{1}, d_{2}\right) \mid\left(D_{1}\right)_{\alpha}^{\mathrm{L}} \leq d_{1} \leq\left(D_{1}\right)_{\alpha}^{\mathrm{U}},\left(D_{2}\right)_{\alpha}^{\mathrm{L}} \leq d_{2} \leq\left(D_{2}\right)_{\alpha}^{\mathrm{U}}\right\},
$$

$$
\left(Z_{S}\right)_{\alpha}^{\mathrm{U}}=\max \left\{Z\left(d_{1}, d_{2}\right) \mid\left(D_{1}\right)_{\alpha}^{\mathrm{L}} \leq d_{1} \leq\left(D_{1}\right)_{\alpha}^{\mathrm{U}},\left(D_{2}\right)_{\alpha}^{\mathrm{L}} \leq d_{2} \leq\left(D_{2}\right)_{\alpha}^{\mathrm{U}}\right\},
$$

which can be, respectively, reformulated as this pair of twolevel quadratic programs following (12):

$$
\begin{array}{r}
\left(Z_{S}\right)_{\alpha}^{\mathrm{L}}=\min _{\substack{\left(D_{1}\right)_{\alpha}^{\mathrm{L}} \leq d_{1} \leq\left(D_{1}\right)_{\alpha}^{\mathrm{U}} \\
\left(D_{2}\right)_{\alpha}^{\mathrm{L}} \leq d_{2} \leq\left(D_{2}\right)_{\alpha}^{\mathrm{U}}}} \begin{cases}\max & (w-c)\left(Q_{1}^{*}+Q_{2}^{*}\right) \\
\text { s.t. } & w \geq c+\varepsilon, \\
& Q_{1}^{*}, Q_{2}^{*} \geq 0,\end{cases} \\
\left(Z_{S}\right)_{\alpha}^{\mathrm{U}}=\max _{\substack{\left(D_{1}\right)_{\alpha}^{\mathrm{L}} \leq d_{1} \leq\left(D_{1}\right)_{\alpha}^{\mathrm{U}} \\
\left(D_{2}\right)_{\alpha}^{\mathrm{L}} \leq d_{2} \leq\left(D_{2}\right)_{\alpha}^{\mathrm{U}}}} \begin{cases}\max & (w-c)\left(Q_{1}^{*}+Q_{2}^{*}\right) \\
\text { s.t. } & w \geq c+\varepsilon, \\
& Q_{1}^{*}, Q_{2}^{*} \geq 0,\end{cases}
\end{array}
$$

where $Q_{1}^{*}$ and $Q_{2}^{*}$ are given by Eqs. (8a) and (8b), respectively.

The operation of this pair of two two-level quadratic programs is as follows. The second-level (inner) program calculates the supplier's maximum profit for each $d_{1}$ or $d_{2}$ specified by the first-level (outer) program, whereas the firstlevel program determines the value of $d_{1}$ or $d_{2}$ that generates the smallest or largest values for this profit.

Solving Model (17a) is less straightforward because its firstand second-level programs have different directions for optimization. A transformation is required to make an optimal solution obtainable. Consider the second-level problem in which $d_{1}$ and $d_{2}$ could be treated as constants such that it is a convex program with a concave objective and a bounded variable. Based on classical optimization theory (Bazaraa et al, 2006), the necessary and sufficient conditions for a given $w^{*}$ to be a maximum to the second-level problem of Model (17a) are that there exists $\lambda_{i} \geq 0, i=1,2,3$, such that the KarushKuhn-Tucker (KKT) conditions are satisfied.

Let $\Omega$ be the set of stationary points for the second-level problem of Model (17a). Consequently, Model (17a) can be reformulated as the following traditional one-level quadratic program:

$$
\begin{aligned}
\left(Z_{S}\right)_{\alpha}^{\mathrm{L}}=\min _{w \in \Omega} & (w-c)\left(Q_{1}^{*}+Q_{2}^{*}\right) \\
& \left(D_{1}\right)_{\alpha}^{\mathrm{L}} \leq d_{1} \leq\left(D_{1}\right)_{\alpha}^{\mathrm{U}}, \\
& \left(D_{2}\right)_{\alpha}^{\mathrm{L}} \leq d_{2} \leq\left(D_{2}\right)_{\alpha}^{\mathrm{U}}, \\
& Q_{1}^{*}, Q_{2}^{*} \geq 0 .
\end{aligned}
$$


Note that according to Zadeh's extension principle listed in Eq. (15), at least one of $d_{1}$ or $d_{2}$ must contact the boundary of their $\alpha$-cuts to satisfy $\mu_{\tilde{Z}_{S}}(z)=\alpha$. Consider the following two cases:

Case $1 d_{1}$ contacts the boundary of its $\alpha$-cuts. In this case, a binary variable $y_{1}$ is employed to form the constraint $d_{1}=y_{1}\left(D_{1}\right)_{\alpha}^{\mathrm{L}}+\left(1-y_{1}\right)\left(D_{1}\right)_{\alpha}^{\mathrm{U}}$. Thus, Model (18) can be reformulated as

$$
\begin{aligned}
\left(Z_{S}\right)_{\alpha}^{\mathrm{L}_{1}}=\min _{w \in \Omega} & (w-c)\left(Q_{1}^{*}+Q_{2}^{*}\right) \\
\text { s.t. } & d_{1}=y_{1}\left(D_{1}\right)_{\alpha}^{\mathrm{L}}+\left(1-y_{1}\right)\left(D_{1}\right)_{\alpha}^{\mathrm{U}}, \\
& \left(D_{2}\right)_{\alpha}^{\mathrm{L}} \leq d_{2} \leq\left(D_{2}\right)_{\alpha}^{\mathrm{U}}, \\
& Q_{1}^{*}, Q_{2}^{*} \geq 0, \\
& y_{1}=0 \text { or } 1 .
\end{aligned}
$$

Case $2 d_{2}$ contacts the boundary of its $\alpha$-cuts. Similarly, in this case, Model (18) can be reformulated by employing another binary variable $y_{2}$ as follows:

$$
\begin{aligned}
\left(Z_{S}\right)_{\alpha}^{\mathrm{L}_{2}}=\min _{w \in \Omega} & (w-c)\left(Q_{1}^{*}+Q_{2}^{*}\right) \\
\text { s.t. } \quad & d_{2}=y_{2}\left(D_{2}\right)_{\alpha}^{\mathrm{L}}+\left(1-y_{2}\right)\left(D_{2}\right)_{\alpha}^{\mathrm{U}}, \\
& \left(D_{1}\right)_{\alpha}^{\mathrm{L}} \leq d_{1} \leq\left(D_{1}\right)_{\alpha}^{\mathrm{U}}, \\
& Q_{1}^{*}, Q_{2}^{*} \geq 0, \\
& y_{2}=0 \text { or } 1 .
\end{aligned}
$$

Each of these two models is a conventional linearly constrained quadratic program with a bounded variable and one binary variable, which can be easily solved effectively and efficiently using quadratic programming methods (Bazaraa et al, 2006) and most commercial software. Consequently, the lower bound of the fuzzy maximum profit of the supplier can be set as $\left(Z_{S}\right)_{\alpha}^{\mathrm{L}}=\min \left\{\left(Z_{S}\right)_{\alpha}^{\mathrm{L}_{1}},\left(Z_{S}\right)_{\alpha}^{\mathrm{L}_{2}}\right\}$.

To derive the upper bound of the objective value in Model (17b), because both the first and second levels perform the same maximization operation, Model (17b) can be rewritten as a conventional one-level quadratic program:

$$
\begin{aligned}
\left(Z_{S}\right)_{\alpha}^{\mathrm{U}}=\max _{w} & (w-c)\left(Q_{1}^{*}+Q_{2}^{*}\right) \\
\text { s.t. } & d_{1}=\left(D_{1}\right)_{\alpha}^{\mathrm{U}}, \\
& \left(D_{2}\right)_{\alpha}^{\mathrm{L}} \leq d_{2} \leq\left(D_{2}\right)_{\alpha}^{\mathrm{U}}, \\
& w \geq c+\varepsilon_{3}, \\
& Q_{1}^{*}, Q_{2}^{*} \geq 0 .
\end{aligned}
$$

Similar to the discussion in solving Model (17b), the following two auxiliary quadratic programs are formulated as follows:

$$
\begin{aligned}
\left(Z_{S}\right)_{\alpha}^{\mathrm{U}_{1}}=\max _{w} & (w-c)\left(Q_{1}^{*}+Q_{2}^{*}\right) \\
\text { s.t. } & d_{1}=y_{3}\left(D_{1}\right)_{\alpha}^{\mathrm{L}}+\left(1-y_{3}\right)\left(D_{1}\right)_{\alpha}^{\mathrm{U}}, \\
& \left(D_{2}\right)_{\alpha}^{\mathrm{L}} \leq d_{2} \leq\left(D_{2}\right)_{\alpha}^{\mathrm{U}}, \\
& w \geq c+\varepsilon_{3}, \\
& Q_{1}^{*}, Q_{2}^{*} \geq 0, \\
& y_{3}=0 \text { or } 1 .
\end{aligned}
$$

and

$$
\begin{aligned}
\left(Z_{S}\right)_{\alpha}^{\mathrm{U}_{2}}=\max _{w} & (w-c)\left(Q_{1}^{*}+Q_{2}^{*}\right) \\
\text { s.t. } \quad & d_{2}=y_{4}\left(D_{2}\right)_{\alpha}^{\mathrm{L}}+\left(1-y_{4}\right)\left(D_{2}\right)_{\alpha}^{\mathrm{U}}, \\
& \left(D_{1}\right)_{\alpha}^{\mathrm{L}} \leq d_{1} \leq\left(D_{1}\right)_{\alpha}^{\mathrm{U}}, \\
& w \geq c+\varepsilon_{3}, \\
& Q_{1}^{*}, Q_{2}^{*} \geq 0, \\
& y_{4}=0 \text { or } 1 .
\end{aligned}
$$

Models (21a) and (21b) are linearly constrained quadratic programs with 0-1 variables, and therefore, they can be solved by any quadratic programming solver. The upper bound of the fuzzy maximum profit of the supplier is derived as $\left(Z_{S}\right)_{\alpha}^{\mathrm{U}}=\max \left\{\left(Z_{S}\right)_{\alpha}^{\mathrm{U}_{1}},\left(Z_{S}\right)_{\alpha}^{\mathrm{U}_{2}}\right\}$.

For each possibility level $\alpha$, the $\alpha$-cut of $\tilde{Z}_{S}$ is constructed as the crisp interval $\left[\left(Z_{S}\right)_{\alpha}^{\mathrm{L}},\left(Z_{S}\right)_{\alpha}^{\mathrm{U}}\right]$, and the membership function of $\tilde{Z}_{S}$ can be constructed by enumerating different $\alpha$ values. An attractive feature of the $\alpha$-cut approach is that all $\alpha$-cuts form a nested structure with respect to $\alpha$ (Zimmermann, 2001). That is, for two possibility levels $\alpha_{1}$ and $\alpha_{2}, 0 \leq \alpha_{2}<\alpha_{1} \leq 1$, we have $\left[\left(d_{1}\right)_{\alpha_{1}}^{\mathrm{L}},\left(d_{1}\right)_{\alpha_{1}}^{\mathrm{U}}\right] \subseteq\left[\left(d_{1}\right)_{\alpha_{2}}^{\mathrm{L}},\left(d_{1}\right)_{\alpha_{2}}^{\mathrm{U}}\right]$ and $\left[\left(d_{2}\right)_{\alpha_{1}}^{\mathrm{L}},\left(d_{2}\right)_{\alpha_{1}}^{\mathrm{U}}\right] \subseteq$ $\left[\left(d_{2}\right)_{\alpha_{2}}^{\mathrm{L}},\left(d_{2}\right)_{\alpha_{2}}^{\mathrm{U}}\right]$. The feasible regions defined by $\alpha_{1}$ in Models (18) and (20) are smaller than those defined by $\alpha_{2}$. Thus, $\left(Z_{S}\right)_{\alpha_{1}}^{\mathrm{L}} \geq\left(Z_{S}\right)_{\alpha_{2}}^{\mathrm{L}}$ and $\left(Z_{S}\right)_{\alpha_{1}}^{\mathrm{U}} \leq\left(Z_{S}\right)_{\alpha_{2}}^{\mathrm{U}}$; that is, $\left(Z_{S}\right)_{\alpha}^{\mathrm{L}}$ is nondecreasing with respect to $\alpha$, and $\left(Z_{S}\right)_{\alpha}^{\mathrm{U}}$ is non-increasing with respect to $\alpha$. Consequently, the membership function of $\tilde{Z}_{S}$ can be approximately constructed from the solutions of Models (19a), (19b), (21a) and (21b) by enumerating several different values of $\alpha$. Furthermore, after deriving the lower and upper bounds of the fuzzy objective value, based on Eqs. (2) and (4), we can use this information to construct the membership functions of the fuzzy maximum profit of these two retailers in the SC by deriving the lower and upper bounds of $\tilde{Z}_{r_{1}}$ and $\tilde{Z}_{r_{2}}$, denoted as $\left[\left(Z_{r_{1}}\right)_{\alpha}^{\mathrm{L}},\left(Z_{r_{1}}\right)_{\alpha}^{\mathrm{U}}\right]$ and $\left[\left(Z_{r_{2}}\right)_{\alpha}^{\mathrm{L}},\left(Z_{r_{2}}\right)_{\alpha}^{\mathrm{U}}\right]$, at different $\alpha$ values.

Note that the supplier's maximum profit in the SC derived through the proposed approach is expressed by using a membership function rather than a crisp value; that is, it is a fuzzy performance measure. The benefit of such a fuzzy performance measure is that it maintains the fuzziness of the market data; thus, it is able to more accurately represent a vague $\mathrm{SC}$.

The value of $\alpha$ also can be explained as the degree of uncertainty of the obtained information. A larger $\alpha$ value indicates the higher level of possibility and the lower the degree of uncertainty. Because $\left(Z_{S}\right)_{\alpha}^{\mathrm{L}}\left(\right.$ or $\left(Z_{r_{1}}\right)_{\alpha}^{\mathrm{L}}$ and $\left.\left(Z_{r_{2}}\right)_{\alpha}^{\mathrm{L}}\right)$ is non-decreasing and $\left(Z_{S}\right)_{\alpha}^{\mathrm{U}}$ (or $\left(Z_{r_{1}}\right)_{\alpha}^{\mathrm{U}}$ and $\left.\left(Z_{r_{2}}\right)_{\alpha}^{\mathrm{U}}\right)$ is nonincreasing with respect to $\alpha$, the higher the degree of uncertainty of the obtained information, the smaller (larger) the lower (upper) bound of the maximum profit of each SC member. 


\subsection{Extension}

The proposed analysis method is also applicable to the case with more fuzzy parameters. For example, without a loss of generality, assume that parameter $\theta$ is also a fuzzy number with membership function $\mu_{\tilde{\Theta}}(\theta)$. Then, Model (18) becomes

$$
\begin{aligned}
\left(Z_{S}\right)_{\alpha}^{\mathrm{L}}=\min _{w \in \Omega} & (w-c)\left(Q_{1}^{*}+Q_{2}^{*}\right) \\
\text { s.t. } & \left(D_{1}\right)_{\alpha}^{\mathrm{L}} \leq d_{1} \leq\left(D_{1}\right)_{\alpha}^{\mathrm{U}}, \\
& \left(D_{2}\right)_{\alpha}^{\mathrm{L}} \leq d_{2} \leq\left(D_{2}\right)_{\alpha}^{\mathrm{U}}, \\
& \theta_{\alpha}^{\mathrm{L}} \leq \theta \leq \theta_{\alpha}^{\mathrm{U}}, \\
& Q_{1}^{*}, Q_{2}^{*} \geq 0,
\end{aligned}
$$

where $\theta_{\alpha}^{\mathrm{L}}$ and $\theta_{\alpha}^{\mathrm{U}}$ are the lower and upper bounds of the $\alpha$-cut of $\mu_{\tilde{\Theta}}(\theta)$. According to Zadeh's extension principle listed in Eq. (15), at least one of $d_{1}, d_{2}$, or $\theta$ must contact the boundary of their $\alpha$-cuts to satisfy $\mu_{\tilde{\Theta}}(\theta)=\alpha$. The following three cases are discussed:

Case $1 \quad \mu_{\tilde{D}_{1}}\left(d_{1}\right)=\alpha, \mu_{\tilde{D}_{2}}\left(d_{2}\right) \geq \alpha$, and $\mu_{\tilde{\Theta}}(\theta) \geq \alpha$. Similar to Model (19a) except that adding a new constraint $\theta_{\alpha}^{\mathrm{L}} \leq \theta \leq \theta_{\alpha}^{\mathrm{U}}$, an auxiliary model can be constructed and solved to find $\left(Z_{S}\right)_{\alpha}^{\mathrm{L}_{1}}$.

Case $2 \mu_{\tilde{D}_{2}}\left(d_{2}\right)=\alpha, \mu_{\tilde{D}_{1}}\left(d_{1}\right) \geq \alpha$, and $\mu_{\tilde{\Theta}}(\theta) \geq \alpha$. Similar to Model (19b) except that adding the constraint $\theta_{\alpha}^{\mathrm{L}} \leq \theta \leq \theta_{\alpha}^{\mathrm{U}}$, an auxiliary model can be constructed and solved to find $\left(Z_{S}\right)_{\alpha}^{\mathrm{L}_{2}}$.

Case $3 \mu_{\tilde{\Theta}}(\theta)=\alpha, \mu_{\tilde{D}_{1}}\left(d_{1}\right) \geq \alpha$, and $\mu_{\tilde{D}_{2}}\left(d_{2}\right) \geq \alpha$. In this case, a binary integer is employed to construct the following auxiliary model:

$$
\begin{aligned}
\left(Z_{S}\right)_{\alpha}^{\mathrm{L}_{3}}=\min _{w \in \Omega} & (w-c)\left(Q_{1}^{*}+Q_{2}^{*}\right) \\
\text { s.t. } \quad & \theta=t \theta_{\alpha}^{\mathrm{L}}+(1-t) \theta_{\alpha}^{\mathrm{U}}, \\
& \left(D_{1}\right)_{\alpha}^{\mathrm{L}} \leq d_{1} \leq\left(D_{1}\right)_{\alpha}^{\mathrm{U}}, \\
& \left(D_{2}\right)_{\alpha}^{\mathrm{L}} \leq d_{2} \leq\left(D_{2}\right)_{\alpha}^{\mathrm{U}}, \\
& Q_{1}^{*}, Q_{2}^{*} \geq 0 \\
& t=0 \text { or } 1 .
\end{aligned}
$$

Consequently, the lower bound of the fuzzy maximum profit of the supplier can be set as $\left(Z_{S}\right)_{\alpha}^{\mathrm{L}}=\min \left\{\left(Z_{S}\right)_{\alpha}^{\mathrm{L}_{1}},\left(Z_{S}\right)_{\alpha}^{\mathrm{L}_{2}},\left(Z_{S}\right)_{\alpha}^{\mathrm{L}_{3}}\right\}$. The cases for finding the upper bound $\left(Z_{S}\right)_{\alpha}^{\mathrm{U}}$ can be discussed in the similar manner [as shown in Models (21a) and (21b)].

\section{Analysis}

To illustrate the validity of the modeling and solution approach, the general case with several scenarios is investigated. In a crisp environment, several studies have investigated a two-echelon SC with one supplier and two retailers based on the assumption that market demands are deterministic (e.g., Yang and Zhou, 2006). Here, we analyze the SC with competition in a fuzzy environment that is more suitable for practical situations.

\subsection{Parameter Setting}

The settings for the manufacturing cost $c=2$ and a moderate degree of competition between two retailers $\theta=0.5$ are adopted for the eight scenarios considered. The parameter settings are summarized in the third to sixth columns of Table 1. Several studies noted that it is rather complicated to show analytical results of this type of SC. Moreover, because the analysis in a fuzzy environment is much more complicated than that in a crisp environment, the results are shown numerically in this paper.

Eight scenarios are investigated and their parameter settings are listed in Table 1 . Scenarios 1 and 2 are two special cases with $\tilde{D}_{1}=\tilde{D}_{2}=\tilde{D}$ and $a_{1} \neq a_{2}$, which can be intuitively explained as the market being constrained by the government. Because the market is constrained by government regulations, the retailers confront the same market demand even if they have different levels of sensitivity of sales to price changes (Brabant, 1991). This situation can often be observed in industries that produce goods using resources constrained by planned economy governments. Here, we set $\tilde{D}_{1}=\tilde{D}_{2}=\tilde{D}$ and $a_{1} \neq a_{2}$, where $\tilde{D}=[15,18,22,25], a_{1}=2$ and $a_{2}=1$ in Scenario 1 , and $a_{1}=1$ and $a_{2}=2$ in Scenario 2. In Scenarios 3-7, we investigate the general duopolistic market case with $\tilde{D}_{1} \neq \tilde{D}_{2}$ and $a_{1} \neq a_{2}$, which can be explained as the two retailers confronting various primary market demand and different levels of sensitivity of sales to price changes observed in industries in a market economy (Cowen and Tabarrok, 2015). The total market demand, $\tilde{T}=[30,36,44,50]$, is fixed to the double of $\tilde{D}$. In Scenarios 3 and 4 , let $\tilde{D}_{1}=0.75 \tilde{T}=[22.5,27,33,37.5]$ and $\tilde{D}_{2}=0.25 \tilde{T}=[7.5,9,11,12.5]$; that is, the leader has three times as many primary demands as the follower. An opposite setting is adopted in Scenarios 5 and 6. The difference among Scenarios 3 and 4 is the level of sensitivity of sales to price changes between these two retailers. Scenarios 3 and 4 correspond to cases in which the leader faces moderately larger $\left(a_{1} / a_{2}=2.3\right)$ and slightly smaller $\left(a_{1} / a_{2}=1 / 1.2 \cong 0.83\right)$ sensitivity of sales to price changes with respect to those faced by the follower, respectively. Scenarios 7 and 8, which are extended from Scenarios 1 and 2, are special cases with highdiversity market demands confronted by these two retailers. Scenarios 7 and 8, respectively, correspond to cases in which the leader faces a significantly smaller $\left(a_{1} / a_{2}=1 / 3 \cong 0.3333\right)$ or larger $\left(a_{1} / a_{2}=3\right)$ sensitivity of sales to price changes.

\subsection{Results and Findings}

Based on the solution procedure presented in Section 3, the lower bound $\left(Z_{S}\right)_{\alpha}^{\mathrm{L}}$ and the upper bound $\left(Z_{S}\right)_{\alpha}^{\mathrm{U}}$ of the $\alpha$-cut of $\tilde{Z}_{S}$ at the possibility level $\alpha$ can be obtained by solving a pair of 
Table 1 Data for eight scenarios of the two-stage SC playing a Stackelberg game

\begin{tabular}{llllllll}
\hline Scenarios & $\begin{array}{l}\text { Retailers' } \\
\text { market } \\
\text { description }\end{array}$ & $\begin{array}{l}\tilde{D}_{1} \text { (Stackelberg } \\
\text { leader) }\end{array}$ & $\begin{array}{l}\tilde{D}_{2} \text { (Stackelberg } \\
\text { follower) }\end{array}$ & $a_{1}$ & $a_{2}$ & $\tilde{D}_{1} / a_{1}$ & $\tilde{D}_{2} / a_{2}$ \\
\hline 1 & Constrained by & {$[15,18,22,25]$} & {$[15,18,22,25]$} & 2 & 1 & {$[7.5,9,11,12.5]$} & {$[15,18,22,25]$} \\
2 & government & {$[15,18,22,25]$} & {$[15,18,22,25]$} & 1 & 2 & {$[15,18,22,25]$} & {$[7.5,9,11,12.5]$} \\
3 & General & {$[22.5,27,33,37.5]$} & {$[7.5,9,11,12.5]$} & 2.3 & 1 & {$[9.78,11.74,14.35,16.30]$} & {$[7.5,9,11,12.5]$} \\
4 & duopolistic & {$[22.5,27,33,37.5]$} & {$[7.5,9,11,12.5]$} & 1 & 1.2 & {$[22.5,27,33,37.5]$} & {$[6.25,7.5,9.17,10.42]$} \\
5 & & {$[7.5,9,11,12.5]$} & {$[22.5,27,33,37.5]$} & 1.2 & 1 & {$[6.25,7.5,9.17,10.42]$} & {$[22.5,27,33,37.5]$} \\
6 & & {$[7.5,9,11,12.5]$} & {$[22.5,27,33,37.5]$} & 1 & 2.3 & {$[7.5,9,11,12.5]$} & {$[9.78,11.74,14.35,16.30]$} \\
7 & Special case: & {$[15,18,22,25]$} & {$[15,18,22,25]$} & 1 & 3 & {$[15,18,22,25]$} & {$[5,6,7.33,8.33]$} \\
8 & high-diversity & {$[15,18,22,25]$} & {$[15,18,22,25]$} & 3 & 1 & {$[5,6,7.33,8.33]$} & {$[15,18,22,25]$} \\
& demands & & & & & & \\
\hline
\end{tabular}

Table 2 Lower and upper bounds of the fuzzy maximum profits and optimal pricing decisions of Scenario 1 at six possibility levels $\alpha$

\begin{tabular}{|c|c|c|c|c|c|c|c|c|}
\hline & & $\tilde{Z}_{S}^{*}$ & $\tilde{Z}_{r_{1}}^{*}$ & $\tilde{Z}_{r_{2}}^{*}$ & $\tilde{Z}_{r_{1}}^{*}+\tilde{Z}_{r_{2}}^{*}$ & $\tilde{w}^{*}$ & $\tilde{P}_{1}^{*}$ & $\tilde{P}_{2}^{*}$ \\
\hline \multirow[t]{2}{*}{$\alpha=0$} & $\mathrm{~L}$ & 53.1915 & 2.7569 & 31.5629 & 34.3198 & 8.7402 & 9.9528 & 14.3583 \\
\hline & $\mathrm{U}$ & 165.8116 & 10.0039 & 92.2056 & 102.2094 & 13.9004 & 16.2102 & 23.5027 \\
\hline \multirow[t]{2}{*}{$\alpha=0.2$} & $\mathrm{~L}$ & 58.1904 & 3.0644 & 34.3062 & 37.3706 & 9.0498 & 10.3282 & 14.9070 \\
\hline & $\mathrm{U}$ & 157.2961 & 9.4417 & 87.6717 & 97.1134 & 13.5908 & 15.8348 & 22.9541 \\
\hline \multirow[t]{2}{*}{$\alpha=0.4$} & $\mathrm{~L}$ & 63.4138 & 3.3881 & 37.1637 & 40.5518 & 9.3594 & 10.7037 & 15.4556 \\
\hline & $\mathrm{U}$ & 149.0050 & 8.8958 & 83.2521 & 92.1479 & 13.2811 & 15.4593 & 22.4054 \\
\hline \multirow[t]{2}{*}{$\alpha=0.6$} & $\mathrm{~L}$ & 68.8616 & 3.7281 & 40.1355 & 43.8637 & 9.6690 & 11.0791 & 16.0043 \\
\hline & $\mathrm{U}$ & 140.9384 & 8.3662 & 78.9468 & 87.3130 & 12.9715 & 15.0839 & 21.8567 \\
\hline \multirow[t]{2}{*}{$\alpha=0.8$} & $\mathrm{~L}$ & 74.5339 & 4.0844 & 43.2217 & 47.3060 & 9.9786 & 11.4546 & 16.5530 \\
\hline & $\mathrm{U}$ & 133.0963 & 7.8528 & 74.7558 & 82.6086 & 12.6619 & 14.7084 & 21.3081 \\
\hline \multirow[t]{2}{*}{$\alpha=1.0$} & $\mathrm{~L}$ & 80.4306 & 4.4569 & 46.4221 & 50.8790 & 10.2883 & 11.8300 & 17.1016 \\
\hline & $\mathrm{U}$ & 125.4787 & 7.3557 & 70.6791 & 78.0348 & 12.3523 & 14.3330 & 20.7594 \\
\hline
\end{tabular}

Table 3 Lower and upper bounds of the fuzzy maximum profits and optimal pricing decisions of Scenario 2 at six possibility levels $\alpha$

\begin{tabular}{|c|c|c|c|c|c|c|c|c|}
\hline & & $\tilde{Z}_{S}^{*}$ & $\tilde{Z}_{r_{1}}^{*}$ & $\tilde{Z}_{r_{2}}^{*}$ & $\tilde{Z}_{r_{1}}^{*}+\tilde{Z}_{r_{2}}^{*}$ & $\tilde{w}^{*}$ & $\tilde{P}_{1}^{*}$ & $\tilde{P}_{2}^{*}$ \\
\hline \multirow[t]{2}{*}{$\alpha=0$} & $\mathrm{~L}$ & 52.7593 & 31.7609 & 3.0052 & 34.7661 & 8.6714 & 14.4919 & 9.8972 \\
\hline & $\mathrm{U}$ & 164.6545 & 92.7269 & 10.7979 & 103.5248 & 13.7856 & 23.7309 & 16.1092 \\
\hline \multirow[t]{2}{*}{$\alpha=0.2$} & $\mathrm{~L}$ & 57.7243 & 34.5192 & 3.3368 & 37.8561 & 8.9782 & 15.0462 & 10.2699 \\
\hline & $\mathrm{U}$ & 156.1921 & 88.1693 & 10.1944 & 98.3637 & 13.4787 & 23.1765 & 15.7364 \\
\hline \multirow[t]{2}{*}{$\alpha=0.4$} & $\mathrm{~L}$ & 62.9126 & 37.3924 & 3.6858 & 41.0782 & 9.2851 & 15.6005 & 10.6426 \\
\hline & $\mathrm{U}$ & 147.9529 & 83.7266 & 9.6083 & 93.3349 & 13.1719 & 22.6222 & 15.3637 \\
\hline \multirow[t]{2}{*}{$\alpha=0.6$} & $\mathrm{~L}$ & 68.3241 & 40.3805 & 4.0521 & 44.4326 & 9.5919 & 16.1549 & 11.0153 \\
\hline & $\mathrm{U}$ & 139.9370 & 79.3987 & 9.0395 & 88.4382 & 12.8650 & 22.0679 & 14.9910 \\
\hline \multirow[t]{2}{*}{$\alpha=0.8$} & $\mathrm{~L}$ & 73.9588 & 43.4834 & 4.4358 & 47.9192 & 9.8988 & 16.7092 & 11.3880 \\
\hline & $\mathrm{U}$ & 132.1443 & 75.1857 & 8.4880 & 83.6737 & 12.5582 & 21.5135 & 14.6183 \\
\hline \multirow[t]{2}{*}{$\alpha=1.0$} & $\mathrm{~L}$ & 79.8168 & 46.7011 & 4.8369 & 51.5380 & 10.2056 & 17.2636 & 11.7608 \\
\hline & $\mathrm{U}$ & 124.5749 & 71.0875 & 7.9540 & 79.0415 & 12.2513 & 20.9592 & 14.2456 \\
\hline
\end{tabular}

quadratic programs according to Models (19a) and (19b). The mathematical programming software package Lingo (LINDO Systems Inc., 1999) is used to solve these problems. The lower and upper bounds for the $\alpha$-cuts of these two retailers' fuzzy maximum profits, $\tilde{Z}_{r_{1}}^{*}$ and $\tilde{Z}_{r_{2}}^{*}$, can be solved similarly. Tables 2 through 9 list the lower and upper bounds of the optimal solutions to these eight scenarios at six values for $\alpha, 0$, $0.2,0.4,0.6,0.8$, and 1.0, including the supplier's and the two retailers' maximum profits $\left(\tilde{Z}_{S}^{*}, \tilde{Z}_{r_{1}}^{*}\right.$, and $\left.\tilde{Z}_{r_{2}}^{*}\right)$, as well as the optimal pricing decisions of these SC members $\left(\tilde{w}^{*}, \tilde{P}_{1}^{*}\right.$, and $\tilde{P}_{2}^{*}$ ). Note that even if both of the fuzzy input parameters (the retailers' market bases) are trapezoidal fuzzy numbers, the membership functions of the objective values (the maximum profits) are nonlinear, although they appear to be trapezoidal. This can be evidenced by observing the figures listed in Tables 2 through 9. The values of the lower (or upper) bound of these fuzzy maximum profits and optimal pricing decisions do not lie on a straight linear line. For example, consider the 
Table 4 Lower and upper bounds of the fuzzy maximum profits and optimal pricing decisions of Scenario 3 at six possibility levels $\alpha$

\begin{tabular}{|c|c|c|c|c|c|c|c|c|}
\hline & & $\tilde{Z}_{S}^{*}$ & $\tilde{Z}_{r_{1}}^{*}$ & $\tilde{Z}_{r_{2}}^{*}$ & $\tilde{Z}_{r_{1}}^{*}+\tilde{Z}_{r_{2}}^{*}$ & $\tilde{w}^{*}$ & $\tilde{P}_{1}^{*}$ & $\tilde{P}_{2}^{*}$ \\
\hline \multirow[t]{2}{*}{$\alpha=0$} & $\mathrm{~L}$ & 40.7854 & 11.1234 & 5.8921 & 17.0155 & 7.5520 & 9.8135 & 9.9794 \\
\hline & $\mathrm{U}$ & 130.2053 & 35.9248 & 18.3700 & 54.2948 & 11.9200 & 15.9842 & 16.2061 \\
\hline \multirow[t]{2}{*}{$\alpha=0.2$} & $\mathrm{~L}$ & 44.7268 & 12.2129 & 6.4459 & 18.6588 & 7.8141 & 10.1837 & 10.3530 \\
\hline & $\mathrm{U}$ & 123.4163 & 34.0381 & 17.4265 & 51.4646 & 11.6579 & 15.6139 & 15.8325 \\
\hline \multirow[t]{2}{*}{$\alpha=0.4$} & $\mathrm{~L}$ & 48.8499 & 13.3532 & 7.0246 & 20.3779 & 8.0762 & 10.5540 & 10.7266 \\
\hline & $\mathrm{U}$ & 116.8091 & 32.2022 & 16.5079 & 48.7101 & 11.3959 & 15.2437 & 15.4589 \\
\hline \multirow[t]{2}{*}{$\alpha=0.6$} & $\mathrm{~L}$ & 53.1548 & 14.5445 & 7.6282 & 22.1727 & 8.3383 & 10.9242 & 11.1002 \\
\hline & $\mathrm{U}$ & 110.3836 & 30.4173 & 15.6141 & 46.0314 & 11.1338 & 14.8734 & 15.0853 \\
\hline \multirow[t]{2}{*}{$\alpha=0.8$} & $\mathrm{~L}$ & 57.6415 & 15.7866 & 8.2567 & 24.0433 & 8.6003 & 11.2944 & 11.4738 \\
\hline & $\mathrm{U}$ & 104.1399 & 28.6833 & 14.7452 & 43.4285 & 10.8717 & 14.5032 & 14.7117 \\
\hline \multirow[t]{2}{*}{$\alpha=1.0$} & $\mathrm{~L}$ & 62.3100 & 17.0796 & 8.9100 & 25.9896 & 8.8624 & 11.6647 & 11.8474 \\
\hline & $\mathrm{U}$ & 98.0779 & 27.0001 & 13.9012 & 40.9013 & 10.6096 & 14.1330 & 14.3381 \\
\hline
\end{tabular}

Table 5 Lower and upper bounds of the fuzzy maximum profits and optimal pricing decisions of Scenario 4 at six possibility levels $\alpha$

\begin{tabular}{|c|c|c|c|c|c|c|c|c|}
\hline & & $\tilde{Z}_{S}^{*}$ & $\tilde{Z}_{r_{1}}^{*}$ & $\tilde{Z}_{r_{2}}^{*}$ & $\tilde{Z}_{r_{1}}^{*}+\tilde{Z}_{r_{2}}^{*}$ & $\tilde{w}^{*}$ & $\tilde{P}_{1}^{*}$ & $\tilde{P}_{2}^{*}$ \\
\hline \multirow[t]{2}{*}{$\alpha=0$} & $\mathrm{~L}$ & 101.6367 & 65.4735 & 1.0979 & 66.5714 & 13.5413 & 22.0904 & 14.4978 \\
\hline & $\mathrm{U}$ & 302.2331 & 188.0573 & 4.0570 & 192.1143 & 21.9021 & 36.3909 & 23.7408 \\
\hline \multirow[t]{2}{*}{$\alpha=0.2$} & $\mathrm{~L}$ & 110.6642 & 71.0460 & 1.2228 & 72.2688 & 14.0429 & 22.9484 & 15.0524 \\
\hline & $\mathrm{U}$ & 287.1890 & 178.9198 & 3.8268 & 182.7466 & 21.4005 & 35.5329 & 23.1863 \\
\hline \multirow[t]{2}{*}{$\alpha=0.4$} & $\mathrm{~L}$ & 120.0758 & 76.8461 & 1.3544 & 78.2005 & 14.5446 & 23.8064 & 15.6070 \\
\hline & $\mathrm{U}$ & 272.5289 & 170.0098 & 3.6033 & 173.6131 & 20.8988 & 34.6748 & 22.6317 \\
\hline \multirow[t]{2}{*}{$\alpha=0.6$} & $\mathrm{~L}$ & 129.8714 & 82.8737 & 1.4927 & 84.3664 & 15.0462 & 24.6645 & 16.1615 \\
\hline & $\mathrm{U}$ & 258.2529 & 161.3274 & 3.3865 & 164.7139 & 20.3972 & 33.8168 & 22.0771 \\
\hline \multirow{2}{*}{$\alpha=0.8$} & $\mathrm{~L}$ & 140.0508 & 89.1289 & 1.6378 & 90.7666 & 15.5479 & 25.5225 & 16.7161 \\
\hline & $\mathrm{U}$ & 244.3609 & 152.8725 & 3.1765 & 156.0490 & 19.8955 & 32.9588 & 21.5225 \\
\hline \multirow[t]{2}{*}{$\alpha=1.0$} & $\mathrm{~L}$ & 150.6145 & 95.6116 & 1.7895 & 97.4011 & 16.0495 & 26.3805 & 17.2707 \\
\hline & $\mathrm{U}$ & 230.8530 & 144.6451 & 2.9732 & 147.6183 & 19.3939 & 32.1007 & 20.9679 \\
\hline
\end{tabular}

Table 6 Lower and upper bounds of the fuzzy maximum profits and optimal pricing decisions of Scenario 5 at six possibility levels $\alpha$

\begin{tabular}{|c|c|c|c|c|c|c|c|c|}
\hline & & $\tilde{Z}_{S}^{*}$ & $\tilde{Z}_{r_{1}}^{*}$ & $\tilde{Z}_{r_{2}}^{*}$ & $\tilde{Z}_{r_{1}}^{*}+\tilde{Z}_{r_{2}}^{*}$ & $\tilde{w}^{*}$ & $\tilde{P}_{1}^{*}$ & $\tilde{P}_{2}^{*}$ \\
\hline \multirow[t]{2}{*}{$\alpha=0$} & $\mathrm{~L}$ & 104.6954 & 0.7385 & 64.3191 & 65.0576 & 13.7491 & 14.5780 & 21.7691 \\
\hline & $\mathrm{U}$ & 310.9596 & 2.8814 & 184.8826 & 187.7640 & 22.2486 & 23.8857 & 35.8457 \\
\hline \multirow[t]{2}{*}{$\alpha=0.2$} & $\mathrm{~L}$ & 113.9811 & 0.8274 & 69.7986 & 70.6260 & 14.2591 & 15.1364 & 22.6137 \\
\hline & $\mathrm{U}$ & 295.4937 & 2.7132 & 175.8944 & 178.6076 & 21.7386 & 23.3273 & 35.0011 \\
\hline \multirow[t]{2}{*}{$\alpha=0.4$} & $\mathrm{~L}$ & 123.6614 & 0.9214 & 75.5020 & 76.4234 & 14.7691 & 15.6949 & 23.4583 \\
\hline & $\mathrm{U}$ & 280.4222 & 2.5501 & 167.1302 & 169.6803 & 21.2286 & 22.7688 & 34.1565 \\
\hline \multirow[t]{2}{*}{$\alpha=0.6$} & $\mathrm{~L}$ & 133.7361 & 1.0205 & 81.4294 & 82.4499 & 15.2790 & 16.2534 & 24.3029 \\
\hline & $\mathrm{U}$ & 265.7452 & 2.3920 & 158.5900 & 160.9820 & 20.7187 & 22.2103 & 33.3119 \\
\hline \multirow[t]{2}{*}{$\alpha=0.8$} & $\mathrm{~L}$ & 144.2053 & 1.1246 & 87.5807 & 88.7054 & 15.7890 & 16.8118 & 25.1475 \\
\hline & $\mathrm{U}$ & 251.4627 & 2.2390 & 150.2737 & 152.5127 & 20.2087 & 21.6519 & 32.4673 \\
\hline \multirow[t]{2}{*}{$\alpha=1.0$} & $\mathrm{~L}$ & 155.0690 & 1.2338 & 93.9560 & 95.1898 & 16.2990 & 17.3703 & 25.9921 \\
\hline & $\mathrm{U}$ & 237.5746 & 2.0910 & 142.1814 & 144.2724 & 19.6987 & 21.0934 & 31.6227 \\
\hline
\end{tabular}

lower bounds of $\tilde{Z}_{S}^{*}$ listed in Table 2 . The lower bounds of $\tilde{Z}_{S}^{*}$ are 53.1915, 58.1904, and 63.4138 at $\alpha=0,0.2$, and 0.4 , respectively, which do not exactly lie on a straight linear line.

The $\alpha$-cut of $\tilde{Z}_{S}^{*}$ (or $\tilde{Z}_{r_{1}}^{*}$ and $\tilde{Z}_{r_{2}}^{*}$ ) represents the possibility that the maximum profit of the supplier (or retailers 1 and 2) will reside within the associated range. Because the fuzzy maximum profit $\tilde{Z}_{S}^{*}$ (or $\tilde{Z}_{r_{1}}^{*}$ and $\tilde{Z}_{r_{2}}^{*}$ ) lies in a range, different $\alpha$-cuts show different intervals and different uncertainty levels of maximum profit. That is, with an increase in $\alpha$, Tables 2 through 9 provide the least-to-most likely (or most-to-least uncertain) intervals of maximum profits for each scenario. Specifically, the $\alpha=1$ cut has the narrowest interval, indicating the range in which the maximum profit is most likely to occur. At the other extreme, the $\alpha=0$ cut has the widest interval showing the entire possible range of values; however, this widest interval contains the most uncertain information. 
Table 7 Lower and upper bounds of the fuzzy maximum profits and optimal pricing decisions of Scenario 6 at six possibility levels $\alpha$

\begin{tabular}{|c|c|c|c|c|c|c|c|c|}
\hline & & $\tilde{Z}_{S}^{*}$ & $\tilde{Z}_{r_{1}}^{*}$ & $\tilde{Z}_{r_{2}}^{*}$ & $\tilde{Z}_{r_{1}}^{*}+\tilde{Z}_{r_{2}}^{*}$ & $\tilde{w}^{*}$ & $\tilde{P}_{1}^{*}$ & $\tilde{P}_{2}^{*}$ \\
\hline \multirow[t]{2}{*}{$\alpha=0$} & $\mathrm{~L}$ & 41.1929 & 5.8325 & 11.2222 & 17.0547 & 7.5449 & 10.0284 & 9.7538 \\
\hline & $\mathrm{U}$ & 131.5290 & 18.1778 & 36.2320 & 54.4098 & 11.9082 & 16.2925 & 15.8772 \\
\hline \multirow[t]{2}{*}{$\alpha=0.2$} & $\mathrm{~L}$ & 45.1745 & 6.3805 & 12.3209 & 18.7014 & 7.8067 & 10.4042 & 10.1212 \\
\hline & $\mathrm{U}$ & 124.6703 & 17.2444 & 34.3295 & 51.5739 & 11.6464 & 15.9167 & 15.5098 \\
\hline \multirow[t]{2}{*}{$\alpha=0.4$} & $\mathrm{~L}$ & 49.3397 & 6.9531 & 13.4709 & 20.4240 & 8.0685 & 10.7801 & 10.4886 \\
\hline & $\mathrm{U}$ & 117.9952 & 16.3355 & 32.4784 & 48.8139 & 11.3846 & 15.5408 & 15.1424 \\
\hline \multirow[t]{2}{*}{$\alpha=0.6$} & $\mathrm{~L}$ & 53.6886 & 7.5503 & 14.6722 & 22.2225 & 8.3303 & 11.1559 & 10.8560 \\
\hline & $\mathrm{U}$ & 111.5037 & 15.4513 & 30.6785 & 46.1298 & 11.1228 & 15.1650 & 14.7750 \\
\hline \multirow[t]{2}{*}{$\alpha=0.8$} & $\mathrm{~L}$ & 58.2211 & 8.1721 & 15.9248 & 24.0970 & 8.5921 & 11.5318 & 11.2234 \\
\hline & $\mathrm{U}$ & 105.1959 & 14.5917 & 28.9299 & 43.5216 & 10.8610 & 14.7891 & 14.4076 \\
\hline \multirow[t]{2}{*}{$\alpha=1.0$} & $\mathrm{~L}$ & 62.9373 & 8.8185 & 17.2288 & 26.0473 & 8.8539 & 11.9076 & 11.5908 \\
\hline & $\mathrm{U}$ & 99.0717 & 13.7567 & 27.2327 & 40.9893 & 10.5992 & 14.4133 & 14.0402 \\
\hline
\end{tabular}

Table 8 Lower and upper bounds of the fuzzy maximum profits and optimal pricing decisions of Scenario 7 at six possibility levels $\alpha$

\begin{tabular}{|c|c|c|c|c|c|c|c|c|}
\hline & & $\tilde{Z}_{S}^{*}$ & $\tilde{Z}_{r_{1}}^{*}$ & $\tilde{Z}_{r_{2}}^{*}$ & $\tilde{Z}_{r_{1}}^{*}+\tilde{Z}_{r_{2}}^{*}$ & $\tilde{w}^{*}$ & $\tilde{P}_{1}^{*}$ & $\tilde{P}_{2}^{*}$ \\
\hline \multirow[t]{2}{*}{$\alpha=0$} & $\mathrm{~L}$ & 30.3503 & 36.5540 & 0.5267 & 37.0807 & 6.2296 & 12.4056 & 6.6486 \\
\hline & $\mathrm{U}$ & 101.0064 & 106.4578 & 2.9900 & 109.4478 & 9.7160 & 20.2557 & 10.7126 \\
\hline \multirow[t]{2}{*}{$\alpha=0.2$} & $\mathrm{~L}$ & 33.4266 & 39.7190 & 0.6174 & 40.3364 & 6.4388 & 12.8766 & 6.8924 \\
\hline & $\mathrm{U}$ & 95.6040 & 101.2343 & 2.7763 & 104.0106 & 9.5068 & 19.7847 & 10.4688 \\
\hline \multirow[t]{2}{*}{$\alpha=0.4$} & $\mathrm{~L}$ & 36.6514 & 43.0154 & 0.7154 & 43.7308 & 6.6479 & 13.3476 & 7.1363 \\
\hline & $\mathrm{U}$ & 90.3501 & 96.1423 & 2.5799 & 98.7222 & 9.2976 & 19.3137 & 10.2249 \\
\hline \multirow[t]{2}{*}{$\alpha=0.6$} & $\mathrm{~L}$ & 40.0247 & 46.4432 & 0.8205 & 47.2637 & 6.8571 & 13.8186 & 7.3801 \\
\hline & $\mathrm{U}$ & 85.2446 & 91.1816 & 2.3907 & 93.5723 & 9.0884 & 18.8427 & 9.9811 \\
\hline \multirow[t]{2}{*}{$\alpha=0.8$} & $\mathrm{~L}$ & 43.5464 & 50.0023 & 0.9329 & 50.9352 & 7.0663 & 14.2896 & 7.6240 \\
\hline & $\mathrm{U}$ & 80.2876 & 86.3523 & 2.2086 & 88.5609 & 8.8792 & 18.3717 & 9.7373 \\
\hline \multirow[t]{2}{*}{$\alpha=1.0$} & $\mathrm{~L}$ & 47.2166 & 53.6929 & 1.0525 & 54.7454 & 7.2755 & 14.7606 & 7.8678 \\
\hline & $\mathrm{U}$ & 75.4791 & 81.6544 & 2.0338 & 83.6882 & 8.6700 & 17.9007 & 9.4934 \\
\hline
\end{tabular}

Table 9 Lower and upper bounds of the fuzzy maximum profits and optimal pricing decisions of Scenario 8 at six possibility levels $\alpha$

\begin{tabular}{|c|c|c|c|c|c|c|c|c|}
\hline & & $\tilde{Z}_{S}^{*}$ & $\tilde{Z}_{r_{1}}^{*}$ & $\tilde{Z}_{r_{2}}^{*}$ & $\tilde{Z}_{r_{1}}^{*}+\tilde{Z}_{r_{2}}^{*}$ & $\tilde{w}^{*}$ & $\tilde{P}_{1}^{*}$ & $\tilde{P}_{2}^{*}$ \\
\hline \multirow[t]{2}{*}{$\alpha=0$} & $\mathrm{~L}$ & 30.6490 & 0.4507 & 36.3622 & 36.8129 & 6.2755 & 6.6715 & 12.3056 \\
\hline & $\mathrm{U}$ & 101.8113 & 2.6732 & 105.9445 & 108.6177 & 9.7925 & 10.7568 & 20.0855 \\
\hline \multirow[t]{2}{*}{$\alpha=0.2$} & $\mathrm{~L}$ & 33.7491 & 0.5317 & 39.5122 & 40.0439 & 6.4865 & 6.9166 & 12.7724 \\
\hline & $\mathrm{U}$ & 96.3719 & 2.4875 & 100.7446 & 103.2321 & 9.5815 & 10.5117 & 19.6187 \\
\hline \multirow[t]{2}{*}{$\alpha=0.4$} & $\mathrm{~L}$ & 36.9984 & 0.6194 & 42.7931 & 43.4125 & 6.6976 & 7.1617 & 13.2392 \\
\hline & $\mathrm{U}$ & 91.0818 & 2.3085 & 95.6757 & 97.9842 & 9.3705 & 10.2666 & 19.1519 \\
\hline \multirow[t]{2}{*}{$\alpha=0.6$} & $\mathrm{~L}$ & 40.3971 & 0.7137 & 46.2049 & 46.9186 & 6.9086 & 7.4068 & 13.7060 \\
\hline & $\mathrm{U}$ & 85.9410 & 2.1361 & 90.7375 & 92.8736 & 9.1595 & 10.0215 & 18.6851 \\
\hline \multirow[t]{2}{*}{$\alpha=0.8$} & $\mathrm{~L}$ & 43.9452 & 0.8148 & 49.7474 & 50.5622 & 7.1196 & 7.6520 & 14.1728 \\
\hline & $\mathrm{U}$ & 80.9496 & 1.9705 & 85.9302 & 87.9007 & 8.9485 & 9.7763 & 18.2183 \\
\hline \multirow[t]{2}{*}{$\alpha=1.0$} & $\mathrm{~L}$ & 47.6425 & 0.9225 & 53.4208 & 54.3433 & 7.3306 & 7.8971 & 14.6396 \\
\hline & $\mathrm{U}$ & 76.1074 & 1.8115 & 81.2537 & 83.0652 & 8.7374 & 9.5312 & 17.7515 \\
\hline
\end{tabular}

For example, in Scenario 1, although the supplier's maximum profit $\tilde{Z}_{S}^{*}$ is imprecise, its most likely value is within the interval of $[80.43062,125.4787]$ with the lowest degree of uncertainty, and its value cannot fall outside the interval of [53.1915, 165.8116] with the highest degree of uncertainty.

In observing the results presented in Tables 2 through 9, this paper finds that in the downstream market under fuzzy environments, the Stackelberg leader's maximum profit is not necessarily higher than its follower's. This result may be contrary to intuition. In fact, regardless of whether the retailer is the Stackelberg leader, a retailer with a larger reservation (or choke) price obtains absolutely more profit, where the $i$ th retailer's reservation price is defined as $R P_{i}=\left(d_{i}+\right.$ $\left.\theta p_{3-i}\right) / a_{i}, i=1,2$. In Scenarios 1 and 5, the second retailer's reservation price is larger than that of the first retailer; thus, $\tilde{Z}_{r_{1}}^{*}<\tilde{Z}_{r_{2}}^{*}$ absolutely for each $\alpha$, although the first retailer is the 


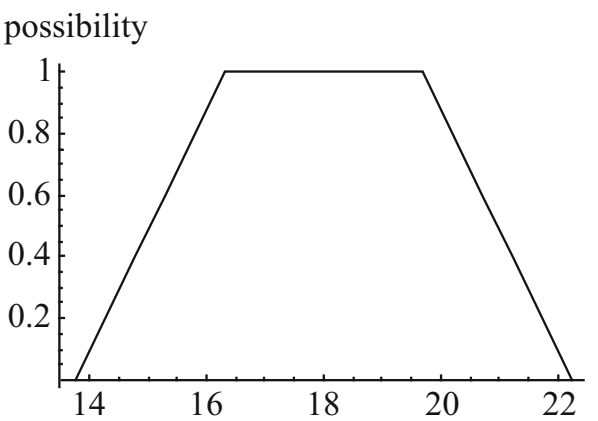

(a) $\tilde{w}^{*}$

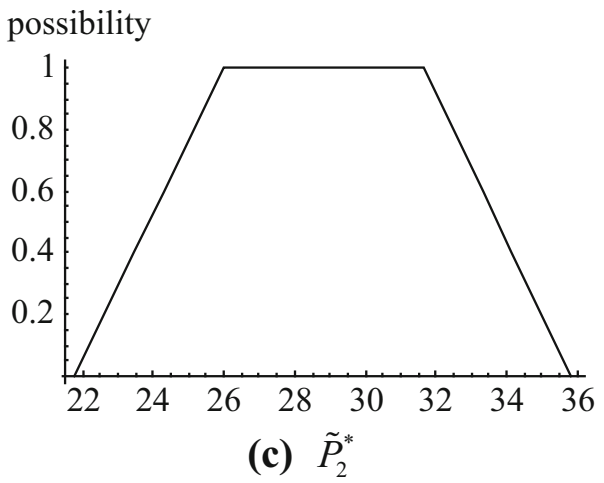

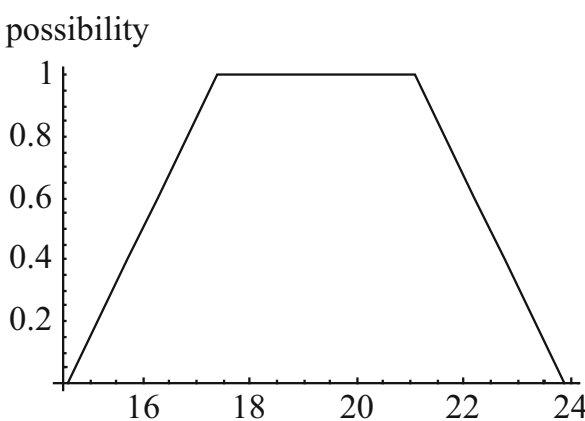

(b) $\tilde{P}_{1}^{*}$

Figure 1 Membership functions of the pricing decisions of SC members for Scenario 6.

Stackelberg leader. For example, consider the case of $\alpha=0$ in Scenario 1 (as shown in the second row of Table 2). The optimal pricing decisions $p_{1}^{*}=9.9528$ and $p_{2}^{*}=14.3583$ occur at $d_{1}^{*}=d_{2}^{*}=15$. Therefore, we have $R P_{2} \cong 19.9764(=(15+$ $0.5 \times 9.9528))>R P_{1} \cong 11.0896(=(15+0.5 \times 14.3583) / 2)$, which results in $\tilde{Z}_{r_{1}}^{*}<\tilde{Z}_{r_{2}}^{*}$. In contrast, in Scenarios 2 and 4, the first retailer has a larger reservation price; thus, $\tilde{Z}_{r_{1}}^{*}>\tilde{Z}_{r_{2}}^{*}$ absolutely for each $\alpha$. In particular, the results obtained from Scenarios 7 and 8 confirm this finding. In Scenario 8, as shown in the fourth and fifth columns of Table 9, although the retailers confront the same market demand, for all possibility levels $\alpha$, the follower's maximum profits are much larger than the corresponding leader's maximum profits because the sensitivity of the leader's sales to price changes is triple that of the follower; that is, $a_{1}=3$ and $a_{2}=1$. As shown in the fourth and fifth columns of Table 8 , the opposite results are obtained in Scenario 7, with $a_{1}=1$ and $a_{2}=3$.

Notably, the maximum profit of the more powerful supplier is not always higher than the total maximum fuzzy profit of the duopolistic retailers and is even smaller than that of the more profitable retailer with a larger reservation price. For example, consider the results for $\alpha=1$ in Scenario 7 (as shown in the third to sixth columns of Table 8). The lower bound of the fuzzy maximum profit of the supplier is derived as $\left(\tilde{Z}_{S}^{*}\right)_{\alpha=1}^{\mathrm{L}}=47.2166$, which occurs at $w^{*}=7.2755$. However, the corresponding lower bounds of the two retailers are $\left(\tilde{Z}_{r_{1}}^{*}\right)_{\alpha=1}^{\mathrm{L}}=53.6929$ and $\left(\tilde{Z}_{r_{2}}^{*}\right)_{\alpha=1}^{\mathrm{L}}=1.0525, \quad$ respectively.
Clearly, both the first retailer's maximum profit $\left(\tilde{Z}_{r_{1}}^{*}\right)_{\alpha=1}^{\mathrm{L}}$ and the total maximum fuzzy profit of the duopolistic retailers $\left(\left(\tilde{Z}_{r_{1}}^{*}\right)_{\alpha=1}^{\mathrm{L}}+\left(\tilde{Z}_{r_{2}}^{*}\right)_{\alpha=1}^{\mathrm{L}}=54.7454\right)$ are higher than the maximum profit of the more powerful supplier. The reason for this is that $a_{2}$ (the sensitivity of the first retailer's sales to changes in its price) is as large as 3 (compared to $a_{1}=1$ and $\theta=0.5$ ) and $\tilde{D}_{1}=\tilde{D}_{2}$ such that the degree of demand diversity of these two retailers is sufficiently large. Here, the degree of demand diversity is defined as the absolute value of the difference between two reservation prices of two retailers: $D D=$ $\left|R P_{1}-R P_{2}\right|$. In this situation, the degree of demand diversity calculated as $D D=\left|R P_{1}-R P_{2}\right| \cong|21.9339-8.4601|=$ 13.4738 is sufficiently large such that the first retailer is mainly responsible for the market demand $\left(Q_{1}^{*}=7.1733>\right.$ $\left.Q_{2}^{*}=1.7769\right)$, even if his pricing is higher than his rival's $\left(p_{1}^{*}=14.7606>p_{2}^{*}=7.8678\right)$. Consequently, the maximum profit of the first retailer, who has a much larger reservation price, is higher than that of his rival and even the more powerful supplier. Another worthwhile aspect is that the fuzzy retailer's profit associated with the smallest market base does not need to be the lowest. The lower bound of $\left(\tilde{Z}_{r_{1}}^{*}\right)_{\alpha=1}^{\mathrm{L}}=$ 0.005780 occurs at $d_{1}^{*}=10.82$ and $d_{2}^{*}=27$, where $d_{1}^{*}=$ $10.82 \in[9,11]$ is not an extreme.

Tables 2 through 9 also show the impact of fuzzy market demand on the pricing decisions $\tilde{w}^{*}, \tilde{p}_{1}^{*}$ and $\tilde{p}_{2}^{*}$. For example, the values listed in the last three columns of Table 6 
Table 10 Effects of downstream market variations on the maximum profits of SC members

\begin{tabular}{|c|c|c|c|c|c|c|c|}
\hline \multicolumn{2}{|c|}{ Scenarios } & \multicolumn{2}{|c|}{ Variation of the primary demand } & \multicolumn{4}{|c|}{ Variation of the SC member's profit } \\
\hline & & $\begin{array}{c}\text { Stackelberg } \\
\text { leader } \\
{\left[\left(\tilde{D}_{1}^{\mathrm{U}}\right)_{\alpha}-\left(\tilde{D}_{1}^{\mathrm{L}}\right)_{\alpha}\right] /} \\
a_{1}\end{array}$ & $\begin{array}{c}\text { Stackelberg } \\
\text { follower } \\
{\left[\left(\tilde{D}_{2}^{\mathrm{U}}\right)_{\alpha}-\left(\tilde{D}_{2}^{\mathrm{L}}\right)_{\alpha}\right] /} \\
a_{2}\end{array}$ & $\begin{array}{c}\text { Upstream } \\
\left(Z_{S}^{\mathrm{U}}\right)_{\alpha}-\left(Z_{S}^{\mathrm{L}}\right)_{\alpha}\end{array}$ & $\begin{array}{c}\text { Downstream } \\
\left(Z_{r_{1}}^{\mathrm{U}}\right)_{\alpha}-\left(Z_{r_{1}}^{\mathrm{L}}\right)_{\alpha}+\left(Z_{r_{2}}^{\mathrm{U}}\right)_{\alpha}-\left(Z_{r_{2}}^{\mathrm{L}}\right)_{\alpha}\end{array}$ & $\begin{array}{c}\text { Stackelberg } \\
\quad \text { leader } \\
\left(Z_{r_{1}}^{\mathrm{U}}\right)_{\alpha}-\left(Z_{r_{1}}^{\mathrm{L}}\right)_{\alpha}\end{array}$ & $\begin{array}{c}\text { Stackelberg } \\
\text { follower } \\
\left(Z_{r_{2}}^{\mathrm{U}}\right)_{\alpha}-\left(Z_{r_{2}}^{\mathrm{L}}\right)_{\alpha}\end{array}$ \\
\hline \multirow[t]{2}{*}{1} & $\alpha=0$ & 5 & 10 & 112.6201 & 67.8896 & 7.2470 & 60.6426 \\
\hline & $\alpha=1$ & 2 & 4 & 45.0481 & 27.1558 & 2.8988 & 24.2570 \\
\hline \multirow[t]{2}{*}{2} & $\alpha=0$ & 10 & 5 & 111.8952 & 68.7587 & 60.9660 & 7.7927 \\
\hline & $\alpha=1$ & 4 & 2 & 44.7581 & 27.5035 & 24.3864 & 3.1171 \\
\hline \multirow[t]{2}{*}{3} & $\alpha=0$ & 6.5217 & 5 & 89.4199 & 37.2793 & 24.8013 & 12.4779 \\
\hline & $\alpha=1$ & 2.6087 & 2 & 35.7680 & 14.9117 & 9.9205 & 4.9912 \\
\hline \multirow[t]{2}{*}{4} & $\alpha=0$ & 15 & 4.1667 & 200.5964 & 125.5429 & 122.5838 & 2.9591 \\
\hline & $\alpha=1$ & 6 & 1.6667 & 80.2385 & 50.2172 & 49.0335 & 1.1836 \\
\hline \multirow[t]{2}{*}{5} & $\alpha=0$ & 4.1667 & 15 & 206.2642 & 122.7064 & 2.1429 & 120.5635 \\
\hline & $\alpha=1$ & 1.6667 & 6 & 82.5056 & 49.0826 & 0.8572 & 48.2254 \\
\hline \multirow[t]{2}{*}{6} & $\alpha=0$ & 5 & 6.5217 & 90.3361 & 37.3551 & 12.3453 & 25.0098 \\
\hline & $\alpha=1$ & 2 & 2.6087 & 36.1344 & 14.9421 & 4.9381 & 10.0039 \\
\hline \multirow[t]{2}{*}{7} & $\alpha=0$ & 10 & 3.3333 & 70.6561 & 72.3671 & 69.9038 & 2.4633 \\
\hline & $\alpha=1$ & 4 & 1.3333 & 28.2625 & 28.9428 & 27.9615 & 0.9813 \\
\hline \multirow[t]{2}{*}{8} & $\alpha=0$ & 3.3333 & 10 & 71.1623 & 71.8048 & 2.2225 & 69.5823 \\
\hline & $\alpha=1$ & 1.3333 & 4 & 28.4649 & 28.7219 & 0.8890 & 27.8329 \\
\hline
\end{tabular}

clearly show that the lower (or upper) bound of these three pricing decisions is a linear function with respect to $\alpha$, as shown in Figure 1. This result can also be verified by observing Eqs. (5), (7), and (10), which are linear functions with respect to $d_{1}$ and $d_{2}$. Furthermore, the higher the degree of uncertainty of the obtained information, the smaller (larger) the lower (upper) bound of each of the SC member's pricing decision $\left(\tilde{w}^{*}, \tilde{P}_{1}^{*}\right.$, or $\left.\tilde{P}_{2}^{*}\right)$.

\section{Discussion}

In practical SC operations, if the market bases are fuzzy numbers, then the maximum profit of each member is also a fuzzy number (i.e., it is a fuzzy performance measure). Note that the maximum profit derived through the proposed approach is expressed by using a membership function rather than a crisp value. The benefit of this fuzzy performance measure is that it completely maintains the fuzziness of the parameters and is thus able to more accurately represent the behavior of a vague SC than a crisp performance measure. This result indicates that the proposed approach can provide more realistic performance measures for the decision makers in a SC when particular SC data are imprecise.

\subsection{Effects of Variations in the Fuzzy Market Base}

To examine the effect of variations in the fuzzy downstream market bases, $\tilde{D}_{1}$ and $\tilde{D}_{2}$, on the maximum profits of chain members of the SC system presented in the previous section for each scenario, Table 10 lists the downstream market variations and the corresponding variations in these three members' maximum profits at the possibility levels $\alpha=0$ and $\alpha=1$. The downstream market variations are measured by the ratio of the interval length over the sensitivity of the retailer's sales to price changes; that is, $\left[\left(\tilde{D}_{i}^{\mathrm{U}}\right)_{\alpha}-\left(\tilde{D}_{i}^{\mathrm{L}}\right)_{\alpha}\right] / a_{i}, i=1,2$, where the values of $a_{1}$ and $a_{2}$ in each scenario are the same as those presented in Table 1. The variations of these three members' maximum profits are measured by $\left(Z_{S}^{\mathrm{U}}\right)_{\alpha}-\left(Z_{S}^{\mathrm{L}}\right)_{\alpha}$, $\left(Z_{r_{1}}^{\mathrm{U}}\right)_{\alpha}-\left(Z_{r_{1}}^{\mathrm{L}}\right)_{\alpha}$, and $\left(Z_{r_{2}}^{\mathrm{U}}\right)_{\alpha}-\left(Z_{r_{2}}^{\mathrm{L}}\right)_{\alpha}$, respectively.

From Table 10, the fuzziness of the downstream market base does indeed have an effect on the maximal profit of each SC member for all scenarios; thus, it also has an effect on the downstream echelon profit and the entire SC profit. As expected, the variation of each SC member's fuzzy maximal profit increases as those of the downstream market bases increase. Moreover, the majority of the variation in the retailer's maximal profit derives from the variation of his market base rather than that of his rival. The most significant examples include Scenarios 7 and 8. Considering the $\alpha=0$ cut of Scenario 7, the variations for the maximal profit of the Stackelberg leader is 69.9038, which is much larger than that of his rival (2.4633), as the variation in the follower's market base is triple that of the leader's market base. However, as shown in the $\alpha=0$ cut of Scenario 8 , the variation in the maximal profit of the Stackelberg leader is 2.2225 , which is much smaller than that of his rival (69.5823). This circumstance also occurs for the pair of Scenarios 4 and 5. For the $\alpha=1$ cut of Scenario 4 , the variation in the leader's market base is 3.6 times $(\cong 6 / 1.6667)$ that of the follower's market base, and the variation for the maximal profit of the leader is 41.4 times $(\cong 49.0335 / 1.1836$ ) that of the follower. The results of Scenarios 7 and 8 listed in Table 10 also show that the variation of the total profit of the duopolistic retailers who act 
Table 11 Marginal variations of the maximum profits of SC members

\begin{tabular}{|c|c|c|c|c|c|c|}
\hline \multirow[t]{2}{*}{ Scenarios } & \multirow{2}{*}{$\begin{array}{l}\text { Total variation of } \\
\text { the primary demand } \\
\left(\mathrm{TV}_{\mathrm{PD}}\right)\end{array}$} & \multicolumn{4}{|c|}{$\begin{array}{c}\text { Marginal contribution of the primary demand to the } S C \\
\text { member's profit }\end{array}$} & \multirow{2}{*}{$\begin{array}{l}\text { Ratio of marginal variation of maximum } \\
\text { profit of the upstream to downstream } \\
\qquad\left(R=\mathrm{MV}_{\mathrm{U}} / \mathrm{MV}_{\mathrm{D}}\right)\end{array}$} \\
\hline & & $\begin{array}{l}\text { Upstream } \\
\left(\mathrm{MV}_{\mathrm{U}}\right)\end{array}$ & $\begin{array}{l}\text { Downstream } \\
\quad\left(\mathrm{MV}_{\mathrm{D}}\right)\end{array}$ & $\begin{array}{l}\text { Stackelberg } \\
\text { leader }\end{array}$ & $\begin{array}{l}\text { Stackelberg } \\
\text { follower }\end{array}$ & \\
\hline 1 & 15 & 7.5080 & 4.5260 & 0.4831 & 4.0428 & 1.6589 \\
\hline 2 & 15 & 7.4597 & 4.5839 & 4.0644 & 0.5195 & 1.6274 \\
\hline 3 & 11.5217 & 7.7610 & 3.2356 & 2.1526 & 1.0830 & 2.3987 \\
\hline 4 & 19.1667 & 10.4659 & 6.5501 & 6.3957 & 0.1544 & 1.5978 \\
\hline 5 & 19.1667 & 10.7616 & 6.4021 & 0.1118 & 6.2903 & 1.6810 \\
\hline 6 & 11.5217 & 7.8405 & 3.2422 & 1.0715 & 2.1707 & 2.4183 \\
\hline 7 & 13.3333 & 5.2992 & 5.4275 & 5.2428 & 0.1847 & 0.9764 \\
\hline 8 & 13.3333 & 5.3372 & 5.3854 & 0.1667 & 5.2187 & 0.9910 \\
\hline
\end{tabular}

as followers will exceed that of the more powerful supplier's profit only when the degree of diversity between the two retailers' market demands is sufficiently high.

Table 11 shows the marginal contributions of the primary demand to the maximum profits of the SC members, where the total variation of the primary demand is calculated by $\mathrm{TV}_{\mathrm{PD}}=$ $\sum_{i=1}^{2}\left[\left(\tilde{D}_{i}^{\mathrm{U}}\right)_{\alpha=0}-\left(\tilde{D}_{i}^{\mathrm{L}}\right)_{\alpha=0}\right] / a_{i}$ and the marginal contributions of the primary demand to the maximum profits of upstream and downstream markets are calculated by $\mathrm{MV}_{U}=\left[\left(Z_{S}^{\mathrm{U}}\right)_{\alpha=0}\right.$ $\left.-\left(Z_{S}^{\mathrm{L}}\right)_{\alpha=0}\right] / \mathrm{TV}_{\mathrm{PD}}$ and $\mathrm{MV}_{D}=\left[\left(Z_{r_{1}}^{\mathrm{U}}\right)_{\alpha=0}-\left(Z_{r_{1}}^{\mathrm{L}}\right)_{\alpha=0}+\left(Z_{r_{2}}^{\mathrm{U}}\right)_{\alpha=0}-\right.$ $\left.\left(Z_{r_{2}}^{\mathrm{L}}\right)_{\alpha=0}\right] / \mathrm{TV}_{\mathrm{PD}}$, respectively (as shown in Table 9). Among three SC members for Scenarios 1-6, the marginal contributions of the primary demand to the supplier's maximum profit are the largest. They range from approximately 7.4597 to 10.7616, which are larger than those of the total profit of the downstream (retail) market, which range from approximately 3.2356 to 6.5501 . However, this finding does not hold for the special cases of Scenarios 7 and 8. For example, in Scenario 7, the marginal contribution of the primary demand to the supplier's maximum profit is 5.2992, which is smaller than that to the total profit of the downstream market $(5.4275$, as shown in the second row of Table 11).

The last column of Table 11 shows the ratio of the marginal contribution of the primary demand to the maximum profit of the upstream market to that of the downstream market for each scenario $\left(R=\mathrm{MV}_{U} / \mathrm{MV}_{D}\right)$. The values of this ratio range from 0.9764 to 2.4183 , where they are larger than 1 for general cases. This result indicates that not only the maximum profit of the upstream market is more sensitive to the imprecision of the primary demands for general cases but also that it is possible that the maximum profit of the downstream market is more sensitive when facing high-diversity retailer markets.

\subsection{Comparison with Stochastic Models}

The results obtained from the proposed method are presented by using membership functions rather than a crisp value (i.e., only the point value); thus, the results obtained from the proposed method based on fuzzy set theory conserve the fuzziness of the input information. By contrast, when the data embedded in the $\mathrm{SC}$, such as the market bases, are only approximately known, the expected values of these market bases are typically employed in the stochastic model to find the optimal solutions. The results obtained from stochastic methods are typically crisp rather than fuzzy, indicating that the optimal total cost may be overestimated or underestimated, as the optimal decision variables would be. Such over- or underestimation not only causes a loss of information (because only point values rather than membership values are obtained) but also distorts the results and undermines the quality of decision making in the SC.

Moreover, fuzzy approaches have certain advantages over stochastic programming approaches, and it is often easier to solve a fuzzy mathematical programming problem than a stochastic programming problem (Inuiguchi and Ramik, 2000; Chen and Ho, 2013). First, the uncertainties embedded in the two-echelon SC investigated here are characterized by ambiguity or vagueness because of an increasingly short PLC and market turbulence. These uncertainties are more suitably described by using fuzzy terms than stochastic terms (Peidro et al, 2009). Moreover, in practice, determining the explicit forms of the probability distributions of market bases in SCs in a short PLC is clearly a challenging or even impossible task. Second, compared with the classic (stochastic) approach, the proposed approach can more easily determine the optimal solutions. For each case, this paper derives the optimal solutions by solving two mathematical programs that are clear, simple, and easy to use. By contrast, the solution procedure for the classic (stochastic) approach typically requires several integrations to be performed in order to find the expectation for the market bases.

\section{Conclusion}

Today, SCM problems suffer from non-stochastic uncertainties because of increasingly short PLCs. This paper devises an analysis method based on the extension principle to provide possible intervals of equilibrium and performance measures 
with a known degree of uncertainty for decision making in a two-echelon SC in which a Stackelberg game in both intraand inter-echelon is played, where market bases are fuzzy rather than numeric or stochastic. A pair of two-level quadratic programming models is developed to calculate the lower and upper bounds of the fuzzy maximum profit at a certain possibility level, and its membership function is then obtained by enumerating the different possibility levels. Eight scenarios that consider different types of downstream markets and sensitivities of the retailer's sales to changes in his opponent's price are successfully analyzed. Furthermore, the effects of the variations in imprecise data on the variations of maximum profits are also investigated to demonstrate the necessity of the proposed modeling and analysis.

The analysis results show that the higher the degree of uncertainty of the obtained information, the smaller (larger) the lower (upper) bound of the maximum profit of each SC member. In addition, the results obtained from eight scenarios include (1) the higher the degree of uncertainty of the obtained information, the smaller (larger) the lower (upper) bound of the pricing of each SC member; (2) in the downstream market, regardless of whether the retailer is the Stackelberg leader, the retailer with a larger reservation price obtains absolutely more profit. Moreover, this paper finds that, when the degree of demand diversity between the two retailers is significantly high, (3) the Stackelberg leader is most likely to obtain lower profit; and (4) the marginal contribution of the primary demand to the total profit of the duopolistic retailers will exceed that of the powerful supplier's maximum profit.

Although the discussion in this paper focuses on the case in which the SC members play a Stackelberg game, it is clear that the methodology can be extended to other game structures, such as Cournot, Collusion, and Nash games. Moreover, in this study, the membership function of each SC member's fuzzy maximum profit is derived numerically. Because of the high levels of complexity and generality of this decision-making problem focused on a SC playing a game in a fuzzy environment, no analytical closed form is provided. Deriving the analytical closed form of the membership function would be a challenging but useful avenue for future research.

Acknowledgements-This research is supported by the Outstanding Young Scholar Plan of the National Science Council of Taiwan under Contract No. NSC100-2628-H-194-003-MY3. The authors are grateful to the Editors, and to the three anonymous reviewers for their valuable comments and suggestions, which have led to significant improvements in this paper.

\section{References}

Bazaraa MS, Sherali HD and Shetty CM (2006). Nonlinear Programming: Theory and Algorithms, 3rd ed. Wiley-Interscience: New York.

Bellman RE, Zadeh LA (1970). Decision-making in a fuzzy environment. Management Science 17(4):B-141-B-164.

Berndt E (1991). The Practice of Econometrics. Addison-Wesley: Boston, MA.
Bilgiç T and Türkşen IB (2000). Measurement of membership functions: Theoretical and empirical work. In: Dubois D and Prade H (eds) Fundamentals of Fuzzy Sets. Kluwer Academic Publishers, New York, pp 195-227.

Brabant JM (1991). The Planned Economies and International Economic Organizations. Cambridge University Press: New York.

Chen F (1999). Decentralized supply chains subject to information delays. Management Science 45(8):1076-1090.

Chen SP and Ho YH (2013). Optimal inventory policy for the fuzzy newsboy problem with quantity discounts. Information Sciences 228:75-89.

Chen YF, Drezner Z, Ryan JK and Simchi-Levi D (2000). Quantifying the bullwhip effect in a simple supply chain: The impact of forecasting, lead times and information. Management Science 46(3):436-443.

Chick SE, Mamani H and Simchi-Levi D (2008). Supply chain coordination and influenza vaccination. Operations Research 56(6): 1493-1506.

Choi SC (1991). Price competition in a channel structure with a common retailer. Marketing Science 10(4):271-296.

Choi S (1996). Price competition in a duopoly common retailer channel. Journal of Retailing 72(2):117-134.

Cowen T and Tabarrok A (2015). Modern Principles of Economics, 3rd ed. Worth Publishers, New York.

Domain-b.com (2008). Tesco Plans to Beat Wal-Mart's First Mover Advantage in India. http://www.domain-b.com/industry/Retail/ 20080816_tesco_plans.html. Accessed 6 June 2009.

Dean J (1980). Estimating the price elasticity of demand. In: Mansfield E (ed) Managerial Economics and Operations Research, 4th ed. Norton, New York.

Ertek G and Griffin PM (2002). Supplier- and buyer-driven channels in a two-stage supply chain. IIE Transactions 34(8):691-700.

Farahani RZ, Rezapour S, Drezner T and Fallah S (2014). Competitive supply chain network design: An overview of classifications, models, solution techniques and applications. Omega 45:92-118.

Giannoccaro I, Pontrandolfo P and Scozzi B (2003). A fuzzy echelon approach for inventory management in supply chains. European Journal of Operational Research 149(1):185-196.

Graves SC and Willems SP (2005). Optimizing the supply chain configuration for new products. Management Science 51(8):1165-1180.

Gunasekaran A, Laib K and Cheng TCE (2008). Responsive supply chain: A competitive strategy in a networked economy. Omega 36(4):549-564.

Iida T and Zipkin P (2010). Competition and cooperation in a twostage supply chain with demand forecasts. Operations Research 58(5): $1350-1363$.

Ingene CA and Parry ME (1995). Channel coordination when retailers compete. Marketing Science 14(4):360-377.

Inuiguchi M and Ramik J (2000). Fuzzy linear programming: A brief review of fuzzy mathematical programming and a comparison with stochastic programming in portfolio selection problem. Fuzzy Sets and Systems 111(1):3-28.

Kouvelis P, Chambers C, Wang H (2006). Supply chain management research and Production and operations management: Review, trends, and opportunities. Production and Operations Management 15(3):449-469.

Kraiselburd S, Narayanan VG and Raman A (2004). Contracting in a supply chain with stochastic demand and substitute products. Production and Operations Management 13(1):46-62.

Krajewski LJ, Ritzman LP and Malhotra MK (2009). Operations Management: Processes and Value Chains, 9th ed. Prentice-Hall, New Jersey.

Lariviere MA (1999). Quantitative Models for Supply Chain Management: Supply Chain Contracting and Coordination with Stochastic Demand. Kluwer Academic Publishers: Norwell, MA. 
Lee HL and Billington C (1992). Managing supply chain inventory: Pitfalls and opportunities. Sloan Management Review 33(3):65-73.

Lee HL, Padmanabhan V and Whang S (1997). The bullwhip effect in the supply chains. Sloan Management Review 38(3):93-102.

LINDO Systems Inc (1999). Lingo User's Guide. LINDO Systems Inc: Chicago.

McGuire TW and Staelin R (1983). An industry equilibrium analysis of downstream vertical integration. Marketing Science 2(2): 161-192.

Miles RE, Snow CC (2007). Organization theory and supply chain management: An evolving research perspective. Journal of Operations Management 25(2):459-463.

Modak NM, Panda S and Sana SS (2016). Three-echelon supply chain coordination considering duopolistic retailers with perfect quality products. International Journal of Production Economics 182: 564-578.

Peidro D, Mula J, Poler R and Verdegay JL (2009). Fuzzy optimization for supply chain planning under supply, demand and process uncertainties. Fuzzy Sets and Systems 160(18): 2640-2657.

Petrovic D, Roy R and Petrovic R (1998). Modelling and simulation of a supply chain in an uncertain environment. European Journal of Operational Research 109(2):299-309.

Petrovic D, Roy R, Petrovic R (1999). Supply chain modelling using fuzzy sets. International Journal of Production Economics 59(1-3):443-453.

Petrovic D (2001). Simulation of supply chain behaviour and performance in an uncertain environment. International Journal of Production Economics 71(1-3):429-438.

Ryan T (2008). Tesco Follows Walmart into India. http://www. retailwire.com/discussion/tesco-follows-walmart-into-india/. Accessed 6 June 2009.

Simchi-Levi D, Kaminsky P and Simchi-Levi E (2004). Managing the Supply Chain: The Definitive Guide for the Supply Chain Professional. McGraw-Hill: New York.

Simchi-Levi D, Kaminsky P and Simchi-Levi E (2007). Designing and Managing the Supply Chain: Concepts, Strategies, and Test Studies, 3rd ed. McGraw-Hill, New York.

Thomas CR and Maurice SC (2007). Managerial Economics, 9th ed. McGraw-Hill, New York.

Türkşen IB (1991). Measurement of membership functions and their acquisition. Fuzzy Sets and Systems 40(1):5-38.

von Stackelberg H (1952). The Theory of the Market Economy, Oxford University Press (Translated from Marktform und Gleichgewicht, 1934, Springer).

Wang JT and Shu YF (2005). Fuzzy decision modeling for supply chain management. Fuzzy Sets and Systems 150(1):107-127.

Wang JT and Shu YF (2007). A possibilistic decision model for new product supply chain design. European Journal of Operational Research 177(2):1044-1061.

Wang D, Du G, Jiao RJ, Wu R, Yu J and Yang D (2016). A Stackelberg game theoretic model for optimizing product family architecting with supply chain consideration. International Journal of Production Economics 172:1-18.
Wei J and Zhao J (2016). Pricing decisions for substitutable products with horizontal and vertical competition in fuzzy environments. Annals of Operations Research 242(2):505-528.

Wong BK, Lai VS (2011). A survey of the application of fuzzy set theory in production and operations management: 1998-2009. International Journal of Production Economics 129(1):157-168.

Wu CH, Chen CW, Hsieh CC (2012). Competitive pricing decisions in a two-echelon supply chain with horizontal and vertical competition. International Journal of Production Economics 135(1):265-274.

Xia, Y (2011). Competitive strategies and market segmentation for suppliers with substitutable products. European Journal of Operational Research 210(2): 194-203.

Xiao T, Choi TM and Cheng TCE (2014). Product variety and channel structure strategy for a retailer-Stackelberg supply chain. European Journal of Operational Research 233(1):114-124.

Xie Y, Petrovic D and Burnham K (2006). A heuristic procedure for the two-level control of serial supply chains under fuzzy customer demand. International Journal of Production Economics 102(1): 37-50.

Yager RR (1986). A characterization of the extension principle. Fuzzy Sets and Systems 18(3):205-217.

Yang SL and Zhou YW (2006). Two-echelon supply chain models: Considering duopolistic retailers' different competitive behaviors. International Journal of Production Economics 103(1):104-116.

Yang D, Jiao, JR, Ji Y, Du G, Helo P and Valente A (2015). Joint optimization for coordinated configuration of product families and supply chains by a leader-follower Stackelberg game. European Journal of Operational Research 246(1):263-280.

Zadeh LA (1965). Fuzzy sets. Information and Control 8(3):338-353.

Zadeh LA (1978). Fuzzy sets as a basis for a theory of possibility. Fuzzy Sets and Systems 1(1):3-28.

Zhao J, Tang W and Wei J (2012a). Pricing decision for substitutable products with retail competition in a fuzzy environment. International Journal of Production Economics 135(1):144-153.

Zhao J, Tang W, Zhao R and Wei J (2012b). Pricing decisions for substitutable products with a common retailer in fuzzy environments. European Journal of Operational Research 216(2): 409-419.

Zhao J, Wei J and Li Y (2014). Pricing decisions for substitutable products in a two-echelon supply chain with firms' different channel powers. International Journal Production Economics 153(4):243-252.

Zhou C, Zhao R and Tang W (2008). Two-echelon supply chain games in a fuzzy environment. Computers and Industrial Engineering 55(2):390-405.

Zimmermann HJ (2001). Fuzzy Set Theory and Its Applications, 4th ed. Kluwer-Nijhoff, Boston.

Received 27 August 2015; accepted 4 October 2016 